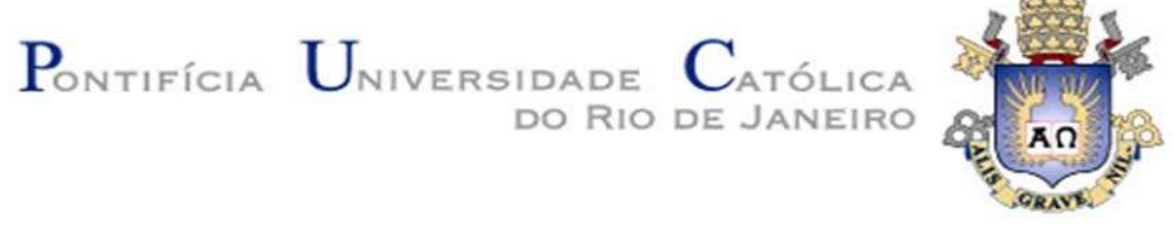

Anelise Palmier Borges de Almeida

Dissertação de Mestrado

Verificação da lucratividade da operação de Carry Trade entre o real e o dólar 2005 a 2016

Dissertação apresentada ao Programa de PósGraduação em Administração de Empresas da PUCRio como requisito parcial para obtenção do grau de Mestre em Administração de Empresas

Orientador: Prof. Antonio Carlos Figueiredo Pinto

Rio de Janeiro Março 2018 


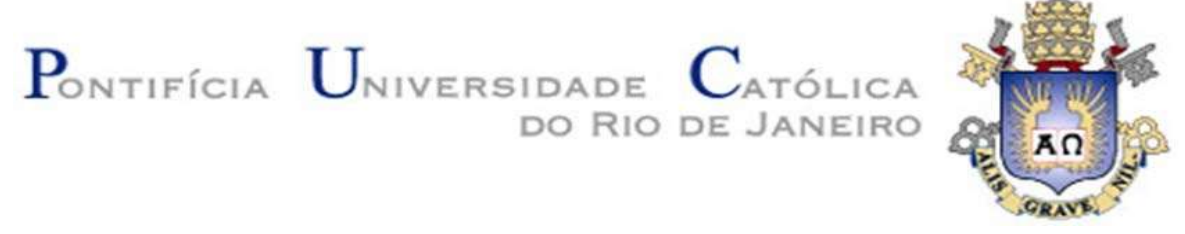

Anelise Palmier Borges de Almeida

\section{Verificação da lucratividade da operação de carry trade entre o Real e o Dólar - 2005 a 2016}

Dissertação apresentada como requisito parcial para obtenção do grau de Mestre pelo Programa de Pósgraduação em Administração de Empresas da PUCRio. Aprovada pela Comissão Examinadora abaixo assinada.

Prof. Antonio Carlos Figueiredo Pinto Orientador Departamento de Administração - PUC-Rio

Prof. Marcelo Cabus Klotzle Departamento de Administração - PUC-Rio

Prof. Marco Antonio Cunha de Oliveira UFRJ

Prof. Augusto Cesar Pinheiro da Silva Coordenador Setorial do Centro de Ciências Sociais - PUC-Rio

Rio de Janeiro, 23 de março de 2018 
Todos os direitos reservados. É proibida a reprodução total ou parcial do trabalho sem autorização da universidade, da autora e do orientador.

\section{Anelise Palmier Borges de Almeida}

Graduação em Administração pela Universidade Federal do Rio de Janeiro (UFRJ) em 2011. Iniciou o mestrado acadêmico na PUC com ênfase em finanças em 2016. Possui mais de 5 anos de experiência no mercado financeiro.

Ficha Catalográfica

Almeida, Anelise Palmier Borges de

Verificação da lucratividade da operação de carry trade entre o real e o dólar - 2005 a 2016 / Anelise Palmier Borges de Almeida ; orientador: Antonio Carlos Figueiredo Pinto. - 2018.

$43 \mathrm{f}$. ; $30 \mathrm{~cm}$

Dissertação (mestrado)-Pontifícia Universidade Católica do Rio de Janeiro, Departamento de Administração, 2018.

Inclui bibliografia

1. Administração - Teses. 2. Paridade descoberta de taxa de juros (PDTJ). 3. Carry trade. I. Pinto, Antonio Carlos Figueiredo. II. Pontifícia Universidade Católica do Rio de Janeiro. Departamento de Administração. III. Título. 


\section{Agradecimentos}

Agradecimento primeiramente à PUC pela oportunidade do mestrado na instituição e aos professores que transmitiram conhecimento acadêmico e orientação ao longo do curso.

À amiga economista Renata Santos de Mello Franco que auxiliou no desenvolvimento dos cálculos da dissertação.

Ao namorado Bruno Osvaldo Leonel, pela paciência, amor e compreensão durante o curso de mestrado.

Ao orientador Prof. Antonio Carlos Figueiredo e Marcelo Cabus Klotzle, por todo o conhecimento transmitido e orientação. 


\section{Resumo}

Almeida, Anelise Palmier Borges de; Pinto, Antonio Carlos Figueiredo. Verificação da lucratividade da operação de Carry Trade entre o real e o dólar - 2005 a 2016. Rio de Janeiro, 2017. 43p. Dissertação de Mestrado - Departamento de Administração, Pontifícia Universidade do Rio de Janeiro.

O presente trabalho visa verificar a operação de carry trade. A lucratividade desta operação é observada quando a diferença de taxa de juros entre os dois países em análise é maior que a variação cambial do período. A verificação da operação, conforme literatura do tema, é realizada através do modelo de paridade descoberta de taxa de juros (PDTJ). A rejeição do modelo, vista através de regressão, possibilita a aceitação da lucratividade da operação. Este estudo, portanto, analisa esta operação entre o Brasil, país de alta taxa de juros e Estados Unidos, país de baixa taxa de juros. Ademais, o estudo visa analisar a operação em um momento de instabilidade econômica, período de 2005 a2016, no qual consta a crise de 2008 que impactou fortemente as duas economias.

\section{Palavras-Chave}

Paridade descoberta de taxa de juros (PDTJ); Carry Trade 


\title{
Abstract
}

\begin{abstract}
Almeida, Anelise Palmier Borges de; Pinto, Antonio Carlos Figueiredo (Advisor). Profitability check of carry trade operation between real and dollar, 2005 a 2016. Rio de Janeiro, 2017. 43p. Dissertação de Mestrado Departamento de Administração, Pontifícia Universidade do Rio de Janeiro.
\end{abstract}

The present work aims to check the carry trade operation. The profitability of this operation is observed when the interest rate difference between the two countries under analysis is greater than the exchange variation for the same period. The literature of carry trade is verified through the uncovered interest rate parity model (UIP). Rejection of the model, performed through regression, makes it possible to accept the profitability of the operation. This study, therefore, analyzes this operation between Brazil, a country with high interest rates and the United States, a country with low interest rates. In addition, the study aims to analyze the operation in a time of economic instability, from 2005 to2016, which includes the crisis of 2008 that strongly impacted the two economies.

\section{KeyWords}

Uncovered interest rate parity (UIP); Carry Trade 


\section{Sumário}

1. Introdução 10

1.1 Contexto do período em análise 10

1.2. Mercado de câmbio no Brasil 12

1.3 Objetivo 13

1.4 Relevância do estudo 13

1.5 Organização do trabalho 14

2. Revisão Bibliográfica 15

2.1 Teoria de Paridade de Taxa de Juros (PTJ) e

Paridade Descoberta de Taxa de Juros (PDTJ) 15

2.2 Literatura Carry Trade 18

2.3 Estudos do Modelo de Paridade Descoberta de Taxa de Juros no Brasil 20

3. Metodologia 22

3.1 Modelo Estatístico 22

3.2 Coleta de Dados 23

4. Desenvolvimento 25

5. Conclusão 33

6. Referências bibliográficas 35

7. Anexos 38 


\section{Lista de figuras}

Figura 1 - Meta Taxa de Juros Brasil e Estados Unidos

Figura 2 - Diferença de Taxa de Juros Brasil x Estados Unidos

Figura 3 - Retorno Câmbio Real/Dólar (2005-2016)

Figura 4 - Retorno Carry Trade (2005-2011)

Figura 5 - Figura de dispersão de diferença de taxa de juros e depreciação da taxa de câmbio brasileira 


\section{Lista de tabelas}

Tabela 1 - Estatística dos Retornos da Variação Cambial (R\$/US\$) entre 2005 e 2016

Tabela 2 - Estatísticas dos Retornos das curvas de juros do Brasil e Estados Unidos - 2005 a 2016

Tabela 3 - Matriz de correlação Retorno Câmbio,

Curva de Juros Brasil e Estados Unidos

Tabela 4 - Matriz de correlação Retorno Câmbio e Diferencial de Juros

Tabela 5 - Teste Dickey Fuller Aumentado (2005 -2016)

Tabela 6 - Regressão MQO (2005-2016)

Tabela 8: Séries swap DIxPRE, Zero Cupom Yield e Retorno do Câmbio (2005-2016) 


\section{Introdução}

A operação conhecida como carry trade é observada através da não verificação do modelo de paridade descoberta de taxa de juros. O modelo por sua vez, defende a ideia de que a diferença de taxa de juros entre os países é compensada pela variação do câmbio. Desta forma, qualquer diferença ou alteração na taxa de juros seria compensada por um movimento no câmbio. Estudos, no entanto, contestam a aplicação deste modelo de forma prática destacando que em muitos casos a sua aplicabilidade é válida apenas no curto prazo, períodos inferiores a um ano.

A operação de carry trade, desta forma, ocorre quando o investidor observa que as oscilações do câmbio não acompanham diretamente a diferença de taxa de juros entre os países. Logo, a operação objetiva a realização de um empréstimo em moeda de baixa taxa de juros, moeda de financiamento e realização da compra de um ativo em outra moeda com alta taxa de juros, moeda alvo. O carry trade, portanto, apenas se torna lucrativo caso o ganho da diferença de taxa de juros seja superior às variações cambiais. $\mathrm{O}$ uso da alavancagem para essa operação, torna tais posições sensíveis às mudanças de taxas de juros e taxas de câmbio (Galati et al., 2007).

Este trabalho visa verificar a lucratividade da operação de carry trade entre o Brasil e os Estados Unidos entre o período de 2005 a 2016.

\subsection{Contexto do período em análise}

O presente trabalho retrata o período de 2005 a 2016no qual, considerando o início do século XXI, foi marcado por grandes instabilidades econômicas e políticas sob o ponto de visto brasileiro. Dois grandes eventos impactaram a economia brasileira no início do século.

$\mathrm{O}$ ano de 2002, primeiramente, pelas eleições presidenciais. O presidente até então em exercício, Fernando Henrique Cardoso (FHC), governava o país nos últimos oito anos (1995-2002). Neste período o real, moeda em vigor passava por um momento de desvalorização, além de o país ter passado por períodos de alta dívida pública. A eleição de um candidato de oposição ao governo em exercício criava instabilidade no cenário econômico do país. O impacto da eleição, em que 
as pesquisas eleitorais apresentavam uma grande possibilidade da eleição de Luiz Inácio Lula da Silva em detrimento aos demais candidatos foi visualizado de forma expressiva principalmente no câmbio brasileiro em relação ao dólar. Em um período de 6 meses, entre abril de 2002 e outubro de 2002, a moeda americana apresentou valorização de 76\%. O Goldman Sachs, banco com sede nos Estados Unidos, inclusive criou o indicador "lulômetro" para medir o efeito da eleição na cotação do dólar. Ao longo de 2003, após o período de eleitoral, no entanto, o dólar apresentou queda.

Após a crise interna política brasileira em que houve uma desvalorização à moeda local fortemente em 2002, o ano de 2008 foi marcado pela crise econômica que se iniciou nos Estados Unidos.

A crise de 2008 teve início em 2007 no mercado norte-americano de hipotecas de alto risco (subprime), concedido às famílias e/ou investidores que não tem muitas garantias para fazer frente ao pagamento dos empréstimos. O próprio imóvel que originava os empréstimos, logo eram tidos como garantia. A expansão do crédito imobiliário foi incentivada nos Estados Unidos a partir do ano 2000 por taxa de juros baixas e desregulamentação financeira. Com a expansão das condições de financiamento, os preços dos imóveis aumentaram substancialmente, que por sua vez possibilitaram aos mutuários a renovação das hipotecas com a obtenção de novos empréstimos, permitindo assim a quitação do saldo anterior e possibilitando a aquisição de novos imóveis. Diante disso, houve um crescimento de empresas de empréstimos hipotecários, que por sua vez, buscavam companhias consideradas sólidas para securitizar os contratos de empréstimos estabelecidos juntos aos seus clientes. As securitizadoras, por conseguinte, passaram a transacionar os contratos de garantia de forma lucrativa no mercado financeiro, o que incorreu em desconectar a acumulação financeira em relação ao valor real dos bens imobiliários dados em garantia. Como resultado, ocorreu um processo especulativo, com valores dos imóveis cada vez mais elevados. O resultado foram empréstimos para clientes insolventes que não conseguiram quitar as dívidas e como consequências aumento das inadimplências. O governo americano, em 2008, diante de papéis "podres" como ativos das instituições privadas, anunciou alguns pacotes de compra destes ativos, visto que configurava como uma crise de solvência, ou seja, incapacidade sistêmica de pagamento e liquidação das dívidas. No entanto, a intervenção do governo americano não foi suficiente e como resultado culminou na falência do 
banco americano Lehman Brothers assim como perdas bilionários de grandes instituições financeiras tais como o banco americano Merril Lynch e a securitizadora American International Group (AIG).

As perdas das empresas americanas não foi o único impacto visualizado. Diferente do discurso do presidente em exercício, Luiz Inácio Lula da Silva (Lula) que retratou a crise como "marolinha" ${ }^{1}$ ", a repercussão econômica no Brasil é facilmente percebida nos seus indicadores econômicos. A desvalorização do real frente ao dólar foi expressiva e contribuiu para as perdas bilionárias de empresa brasileiras tais como a Sadia, Votorantim e Aracruz Celulose. A redução da liquidez internacional resultou no aumento dos custos de refinanciamento para as brasileiras aliado à queda da demanda e dos preços das principais commodities, que representam a maior parte das exportações brasileiras. Toda essa conjuntura contribuiu para o aumento do risco do país e fuga de capital dos países desenvolvidos no qual buscavam ativos mais seguros. A queda da bolsa de valores brasileira também foi expressiva. A vulnerabilidade da economia brasileira diante à crise teve impacto no aumento da inflação. O governo brasileiro, desta forma adotou medidas para conter os efeitos da crise. Leilões de venda de dólares foram uma tentativa de amenizar a desvalorização da moeda nacional frente às demais moedas e a redução dos depósitos compulsórios objetivou aumentar a oferta de crédito ao público consumidor numa tentativa de induzir o consumo interno (Pires, 2013).

\subsection{Mercado de câmbio no Brasil}

O mercado cambial brasileiro tem algumas particularidades quando comparado aos mercados externos. A primeira delas consiste em não existir a plena conversibilidade da moeda brasileira, ou seja, não é possível realizar transações no país utilizando moedas estrangeiras. Como reflexo da não conversibilidade, o dólar futuro negociado na $\mathrm{B}^{2}$, nova empresa oriunda da junção da BM\&F Bovespa e CETIP, tem um volume maior que o dólar spot ou dólar negociado à vista. Como

\footnotetext{
${ }^{1}$ Lula: crise é tsunami nos EUA e, se chegar ao Brasil, será 'marolinha', O Globo, 04 out. 2008. Lula destacou que a economia brasileira não seria atingida pelos efeitos da crise que se originou nos Estados Unidos.

${ }^{2} \mathrm{O}$ histórico dos volumes negociados diariamente na bolsa de valores é encontrado no site da B3, http://www.bmf.com.br/bmfbovespa/pages/boletim1/VolumeGeral/VolumeGeral.asp
} 
exemplo, apenas em Dezembro de 2005 foram negociados R $\$ 1.078 .055 .201,00 \mathrm{em}$ contratos de futuro de dólar conforme site da B3. Isso ocorre porque qualquer investidor pode negociar dólar futuro, porém nem todos podem negociar dólar spot como investimento ou hedge.

Outro ponto é a intervenção por parte do Banco Central do Brasil (BCE). Essas intervenções ocorrem através de cobrança de impostos nas transações internacionais tais como o Imposto sobre Operações Financeiras (IOF) e Imposto de Renda (IR) ou mesmo através de leilões de dólar spot ou swap cambiais. O Brasil tipicamente utiliza os impostos para realizar ajustes de capital estrangeiro no país. Em 2010, por exemplo, o governo aumentou o IOF para investimento de estrangeiros em títulos de renda fixa local de $2 \%$ para $4 \%$ e depois no mesmo ano para 6\%. Em 2013, no entanto, este tributo foi alterado para zero.

\subsection{Objetivo}

O presente estudo tem como objetivo verificar se a estratégia de carry trade gera lucratividade considerando o Brasil como moeda alvo e o Estados Unidos como moeda de financiamento. O estudo selecionou, desta forma, um país com predominância de alta taxa de juros, Brasil, e o país em que se iniciou a crise de 2008 no qual tem predominância de baixa taxa de juros, os Estados Unidos.

A análise englobou o período de 2005 a 2016no qual consta a crise de 2008 assim como os prazos de 1 a 5 anos. Este período, logo foi verificado por uma grande instabilidade do câmbio, no qual o real não apresentou uma tendência firme, ou seja, ocorreram momentos de desvalorização da moeda verificada fortemente em 2008 e momentos de valorização do câmbio.

\subsection{Relevância do estudo}

As crises políticas e econômicas ocorridas durante o início do século XXI que sensibilizaram a economia brasileira devem ser levadas em consideração nas análises dos resultados. A crise de 2008 impactou não somente o Estados Unidos como também toda a economia global no qual inclui o Brasil. Logo, este trabalho torna-se mais crítico visto que muitos estudos não destacam a predominância de instabilidades econômicas. 
Adicionalmente, a literatura estrangeira, tais como Froot \& Thaler (1990), McCallum \& Bennett (1994), Chinn \& Meredith (2005) consideram predominantemente períodos anteriores ao século XXI no qual utilizam como moeda de referência o dólar.

\subsection{Organização do trabalho}

O trabalho foi dividido nas seguintes partes a serem destacadas. Primeiramente será apresentado o tema através de uma revisão bibliográfica. Esta, por sua vez, destaca o modelo de paridade descoberta de taxa de juros utilizada por este e demais estudos que retratam a questão do carry trade. Juntamente com a exposição das fórmulas do modelo em questão, será exposto os resultados alcançados por estudos similares.

Adicionalmente, serão destacados alguns estudos referentes ao tema realizados no Brasil.

Em seguida, é apresentada a metodologia a ser utilizada no qual faz referência ao modelo de paridade descoberta de taxa de juros assim como o uso de fórmulas e conceitos em paralelo ao modelo utilizado. Seguidamente, são apresentadas as fontes de coletas de dados. O desenvolvimento, subsequente à metodologia, destaca os resultados e suas respectivas análises verificados neste trabalho. Por último, a conclusão apresenta os resultados verificados e sugestões para trabalhos futuros. 


\section{Revisão Bibliográfica}

\subsection{Teoria de Paridade de Taxa de Juros (PTJ) e Paridade Descoberta de Taxa de Juros (PDTJ)}

A verificação da lucratividade nas atividades de carry trade é realizada através do modelo de paridade descoberta de taxa de juros. No entanto, é importante antes o conhecimento da paridade coberta de taxa de juros (PCTJ), conforme expressão abaixo:

$f_{t, t+k}-S, t=\left(i_{t, t+k}-i^{*} t, t+k\right)$

onde $f_{t, t+k}$ e $S, t$ representam o logaritmo natural entre a taxa de câmbio a termo para $\mathrm{k}$ períodos à frente $\left(\mathrm{f}_{\mathrm{t}, \mathrm{t}+\mathrm{k}}\right)$ e o câmbio spot $(\mathrm{s}, \mathrm{t}), \mathrm{i}_{\mathrm{t}, \mathrm{t}+\mathrm{k}} \mathrm{e}^{\mathrm{*}}{ }_{\mathrm{t}, \mathrm{t}+\mathrm{k}}$ representam a taxa de juros do período entre $\mathrm{t}$ e $\mathrm{t}+\mathrm{k}$ respectivamente do país da moeda local e estrangeira. O prêmio a termo (foward premium) situado no lado esquerdo da equação (1) é igual ao diferencial de juros. Desta forma, não é observado a oportunidade de arbitragem e assim o risco é neutro. $\mathrm{O}$ mercado de câmbio brasileiro, conforme destacado pela literatura, apresenta maior liquidez no mercado futuro e as oportunidades de arbitragem ocorrem quando a taxa a termo não é igual a diferença de juros. Entende-se por arbitragem a operação de compra e venda de um mesmo ativo com o objetivo de ganhos econômicos sobre a diferença de preços existente, para um mesmo ativo, entre dois mercados. Trata de uma operação sem risco em que o arbitrador aproveita que o preço do ativo ainda não se ajustou para auferir lucro na operação.

No entanto, a paridade coberta de taxa de juros destaca que a variação futura do câmbio é igual ao diferencial de taxa de juros subtraindo o prêmio de risco

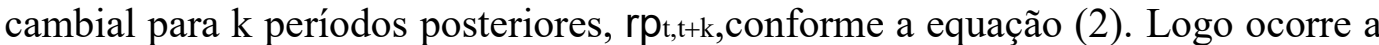
equalização dos ativos em moeda nacional (risco cambial está coberto) e não há ocorrência do risco país. Desta forma, o desvio da paridade coberta de taxa de juros é o risco país no qual quando detectado dá a entender que os ativos nacionais e estrangeiros não são substituídos perfeitamente. Frankel (1991) afirma que a ocorrência deste desvio é a melhor medida da ausência da perfeita mobilidade capital. Nesta equação, $\mathrm{f}_{\mathrm{t}, \mathrm{t}+\mathrm{k}}$ é considerada como a taxa de câmbio a termo e $\mathrm{s}_{\mathrm{t}, \mathrm{t}+\mathrm{k}}^{\mathrm{a}}$ taxa spot esperada no futuro. Conforme Fama (1984), o risco cambial e a 
depreciação esperada da moeda estão negativamente correlacionados, de modo que boa parte do prêmio encontrado (foward preminum) ocorre por conta do risco cambial. Desta forma, a taxa de termo difere da taxa futuro spot e logo o investidor tem um prêmio de forma a compensar o risco de investir em ativos na moeda estrangeira versus na moeda local.

$f_{t, t+k}=s^{e} t, t+k-r p_{t, t+k}$

Uma das premissas do modelo é a hipótese de expectativas racionais, ou seja, os agentes econômicos têm acessos irrestritos às informações. Aplicando no caso brasileiro a expectativa de depreciação do câmbio é verificada nos contratos de mercado futuro negociados na B3. Considerando como exemplo um vencimento de 30 dias dos contratos de futuro de moeda, a diferença entre a taxa a termo (foward preminum) e a expectativa de depreciação da moeda no período é o risco cambial.

Desta forma, substituindo a equação (2) na equação (1) observa-se que a expectativa de depreciação da moeda local está relacionada a diferença de taxa de juros entre os países, conforme equação (3)

$s_{t, t+k}^{e}-s_{, t}=i_{t, t+k}-i^{*} t, t+k-r p t, t+k$

Entretanto, a paridade descoberta de taxa de juros propõe que o prêmio de risco é igual a zero consistente com a suposição de risco neutro. Neste caso, a expectativa de variação do câmbio é igual a diferença das taxas de juros dos países, ou seja, os agentes econômicos são neutros ao risco.

O modelo de expectativas racionais destaca que o agente tem acesso a todas as informações para que a expectativa do câmbio futuro seja realizada, logo não existe risco cambial e, portanto não há ganho na arbitragem. Toda e qualquer diferença do modelo é motivada por erro aleatório. Desta forma, é esperado expectativas racionais no qual a taxa futuro do câmbio $\mathrm{S} t, \mathrm{t}+\mathrm{k}$ é igual ao valor esperado no tempo $t$ adicionado do termo de erro ruido branco. Este erro logo não é correlacionado a nenhuma informação no tempo t, seja a diferença de taxa de juros ou o câmbio, conforme equação (4).

$\mathrm{S}_{\mathrm{t}, \mathrm{t}+\mathrm{k}}=\mathrm{S}_{\mathrm{t}, \mathrm{t}+\mathrm{k}}^{\mathrm{e}}+\boldsymbol{\xi}_{\mathrm{t}, \mathrm{t}+\mathrm{k}}$ 
Desta forma, substituindo a equação (4) na equação (3) temos:

$$
\mathrm{s}_{\mathrm{t}, \mathrm{t}+\mathrm{k}}^{\mathrm{e}}-\mathrm{s}_{\mathrm{t}, \mathrm{t}}=i_{\mathrm{t}, \mathrm{t}+\mathrm{k}}-i^{*} \mathrm{t}, \mathrm{t}+\mathrm{k}-\mathrm{rp}_{\mathrm{t}, \mathrm{t}+\mathrm{k}}+\boldsymbol{\xi}_{\mathrm{t}, \mathrm{t}+\mathrm{k}}
$$

A regressão da paridade de taxa de juros desta forma é demonstrada na equação (6).

$$
\Delta \mathbf{S}_{\mathrm{t}, \mathrm{t}+\mathrm{k}}=\boldsymbol{\alpha}+\beta\left(i_{\mathrm{t}, \mathrm{k}}-i^{*} \mathrm{t}, \mathrm{k}\right)+\boldsymbol{\varepsilon} \mathrm{t,t+ \textrm {k }}
$$

em que $\Delta \mathrm{S}_{\mathrm{t}, \mathrm{t}+\mathrm{k}}$ representa a variação da moeda alvo em $\mathrm{k}$ períodos, it - $\mathrm{i}^{*} \mathrm{t}$ a diferença de taxa de juros entre o país de moeda alvo e país de moeda de financiamento e $\boldsymbol{\varepsilon}, t+\mathrm{k}$ a combinação do risco neutro na equação (3) e as expectativas racionais. A hipótese de risco neutro dos mercados eficientes (RNEMH), por sua vez, defende que os desvios da neutralidade do risco e expectativas racionais não devem ter correlação com a diferença de taxa de juros. Logo, a equação (5) deve ter o risco prêmio igual a zero. Desta forma, a paridade descoberta de taxa de juros pode ser testada considerando o $\alpha=0, \beta=1$ e $\boldsymbol{\varepsilon}_{\mathrm{t}, \mathrm{t}+\mathrm{k}}$ ortogonal as informações disponíveis no tempo t.

Desta forma, considerando o $\beta=1$ e $\alpha=0$, a variação do câmbio seria compensada pela diferença de taxa de juros entre os países. Assim, como exemplo, um aumento de taxa de juros pela política monetária do país impacta a depreciação da moeda local. Por outro lado, o $\beta<0$ implica que uma apreciação do câmbio na moeda local está associada a uma diminuição da diferença de taxa de juros entre os países, assim como o $\beta>1$ tem efeito contrário conforme Froot e Thaler (1990).

O termo $\alpha$ diferente de zero, por usa vez, é consistente com a paridade descoberta de taxa de juros. A desigualdade de Jensen expõe que a expectativa do $\log$ do futuro de câmbio não é igual ao $\log$ da expectativa do futuro de câmbio. Alternativamente, o termo constante reflete o risco prêmio constante demandado pelo investidor no país estrangeiro versus os ativos domésticos. Esse risco, no entanto, pode ser utilizado para diferentes ativos conforme sua classificação de risco. Logo, para ativos lastreados em títulos públicos esse risco pode não ser encontrado (Chinn \& Meredith, 2005). Por outro lado, uma mudança de taxa de juros pode resultar em um maior prêmio de risco (Froot \& Thaler, 1990). 
Froot \& Thaler (1990) em seu estudo destacou um beta médio de $-0,88$. O resultado, por sua vez, pode ser interpretado como um prêmio de risco variável a moeda estrangeira. Chinn \& Meredith (2004), por outro lado, destacou a diferença entre o beta de curto e longo prazo. O período de 1 ano encontrou beta médio igual a $-0,55$, no entanto para períodos maiores observou que a atividade de carry trade deixava de ser lucrativa com um beta crescente e próximo de um entre os prazos de 1 e 5 anos. Deste modo, para o período de 5 anos Chinn \& Meredith (2004) encontraram um beta médio igual a 0,74 . O beta próximo de um também foi observado no trabalho de Chinn \& Meredith (2005). Desta forma, estes estudos demonstram que para período de longo prazo a hipótese de paridade descoberta de taxa de juros é favorável.

\subsection{Literatura Carry Trade}

O desempenho consistente do carry trade foi verificado durante o início dos anos 2000, antes da crise de 2008, entre países com baixa taxa de juros como Japão e Suiça, moeda de financiamento, e países com alta taxa de juros como Austrália e Nova Zelândia. O dólar australiano e dólar da Nova Zelândia tiveram uma apreciação significativa no período destacado, assim como rand da África do Sul (Galati et al., 2007). As moedas asiáticas, principalmente do Japão, Nova Zelândia e Austrália logo se tornaram índice de referência de carry trade, tais como o CSFB Rolling, DB Havest e Intelligent Carry Trade Index (Gyntelberg \& Remolona , 2007).

A operação realizada com o iene como moeda de financiamento e o dólar australiano como moeda alvo, por exemplo, foi altamente lucrativa entre 2003-2007 período em que o câmbio apresentava baixa volatilidade. Instituições financeiras criaram contas margens chamadas de "agregadores de varejo" no qual permitia aos japoneses alavancar suas posições de carry trade de longo ou curto prazo. Durante esse período foi verificado um aumento progressivo de volume de transações cambiais e número de contas no Japão. Porém, em 2008, a moeda australiana foi fortemente desvalorizada e as operações de carry trade apresentaram fortes perdas após um período estável (Zurawski \& D’Arcy, 2009).

Conforme Tse \& Zhao (2012) a lucratividade da operação de carry trade não apenas depende da diferença de taxa de juros como também da baixa volatilidade dos mercados. Por outro lado, ao longo de 2009 o popular carry-trade 
iene e dólar australiano apresentou um impressionante retorno de $40 \%$ devido à apreciação da moeda australiana. Estudos mostram que esta operação é um importante fator que causa oscilações do câmbio. A sua maior procura cria maior demanda pela moeda alvo, por outro lado, alterações na demanda impactam diretamente o câmbio em direção oposta.

O carry trade com retorno positivo é particularmente visto em posições de curto prazo. Chinn \& Meredith (2004) realizaram estudos com os países do G73 para prazos que variaram de 3 meses a 10 anos entre 1980 e 2000 e destacaram que alterações no câmbio no curto prazo conduzem a uma resposta da política monetária do país o que resulta em uma correlação negativa do câmbio com a taxa de juros, ao contrário da hipótese de paridade descoberta de taxa de juros. Por outro lado, o câmbio e a taxa de juros, em uma perceptiva de longo prazo são determinados por fundamentos macroeconômicos e assim são mais consistentes com a paridade descoberta de taxa de juros.

O carry trade tradicionalmente pode ser realizado por diferentes instrumentos financeiros. A forma mais simples, no qual pode ser encontrado nos países em desenvolvimento, consiste na compra da moeda spot (moeda alvo) e a abertura de posições em ativos de curto prazo com o objetivo de manter até o vencimento, tais como títulos do governo e certificados bancários. Adicionalmente, o carry trade é observado em operações com derivativos, o que inclui mercado futuro, termo de moedas e swaps assim como outras opções (Galati et al., 2007).

$\mathrm{Na}$ América Latina, especificamente, são encontrados 3 tipos de estratégias usualmente vistas como investimento na moeda alvo. A primeira envolve a compra de ativos domésticos, no caso do Brasil, por exemplo, títulos do governo NTN-Fs e LTN ou títulos de empresa privadas tais como os certificados de recebíveis imobiliários (CRI) e certificados de recebíveis do agronegócio (CRA). Títulos similares são vistos no Peru, México e Colômbia. As outras estratégias envolvem compra de moeda alvo de forma a fica posicionado em contratos de swaps ou contratos a termo de moeda (BIS PAPERS, 2015).

O carry trade, no entanto, também depende do regime de câmbio adotado pelos países. Em 1999 o Brasil mudou o regime de câmbio semifixo para câmbio

\footnotetext{
${ }^{3}$ G7 são as sete economias mais avançadas do mundo conforme o Fundo Monetário Internacional (FIM) composto pelos países Alemanha, Canadá, Estados Unidos, França, Itália, Japão e Reino Unido.
} 
flutuante assim como introduziu o regime de meta de inflação no mesmo ano. Com a globalização financeira, a maioria dos países emergentes passaram a adotar o regime de câmbio de flutuação suja com graus diferenciados de intervenção no mercado de câmbio pela autoridade monetária. $\mathrm{O}$ mercado financeiro internacional apresentou um elevado crescimento ocasionado tanto pelo aumento do fluxo do comércio exterior quanto pelo aumento vertiginoso do fluxo do movimento de capitais. Esse crescimento, no entanto, foi interrompido pela crise subprime do ano de 2008 .

\subsection{Estudos do Modelo de Paridade Descoberta de Taxa de Juros no Brasil}

Os estudos de análise de paridade descoberta de taxa de juros para o Brasil são abrangentes. Além de verificar diferentes metodologias, foram realizados para diferentes períodos e frequência.

Garcia \& Olivares (2001) através da metodologia de mínimos quadrados ordinários (MQO) utilizaram o arcabouço teórico de Fama (1984) através de dados mensais. O beta encontrado para o período de 1995 a 1998 foi igual a 0,295 e um alfa igual a 0,358 . A hipótese de "eficiência" $\left(H_{o}: \alpha=0, \beta=1\right)$, o que representa a paridade descoberta de taxa de juros, é rejeitada pelo teste Wald.

Carvalho \& Divino (2009) estimaram o modelo através dos mínimos quadrados ordinários (MQO) além do método dos momentos generalizados (GMM). O período de 1995 e 2007 mostrou um beta significante para ambos os modelos igual a 1,012 através do MQO e 1,018 através do GMM, logo a hipótese de paridade descoberta de taxa de juros não é rejeitada o que descarta o carry trade como operação lucrativa. Carvalho \& Divino (2009) destacam no período houve uma crescente mobilidade de capitais e evidenciam o estudo de Edwards \& Khan (1985). Este estudo, por sua vez, considera que sob a hipótese de plena mobilidade de capitais, ausência de arbitragem, previsão perfeita e mercados financeiros internacionais completos, a taxa de juros doméstica de economias abertas em desenvolvimento tende, em média, a seguir à variação da taxa de câmbio e taxa de juros de uma economia desenvolvida.

Silva \& Curado (2013) tratam exclusivamente da economia brasileira entre o período de 2003 e 2008, no qual não há grandes oscilações do câmbio. O estudo utiliza como metodologia a estimação do VAR com os dados das variáveis mensais 
de taxas de câmbio, diferencial de taxa de juros e o prêmio de risco soberano representado pelo embi+. Os resultados não confirmaram a paridade descoberta de taxa de juros e foi verificado que a variação da taxa de câmbio no Brasil foi mais influenciada pelas próprias variações cambiais e pelo risco país. Ademais, a diferença entre taxa de juros entre os países apareceu como uma variável menos relevante para explicar as variações cambiais.

Portanto, os estudos brasileiros apresentam metodologias distintas e utilizam-se de diferentes períodos no qual deve ser levado em consideração na comparação dos resultados. Ademais, os resultados não foram convergentes, no qual houve estudos de aceitação e rejeição do modelo de paridade descoberta de taxa de juros. 


\section{Metodologia}

\subsection{Modelo Estatístico}

O modelo a ser utilizado para cálculo do carry trade é o mesmo destacado pela literatura do tema, ou seja, o modelo de paridade descoberta de taxa de juros, conforme a equação (6) destacada na revisão bibliográfica. O método dos mínimos quadrados ordinários (MQO) foi utilizado na regressão do modelo. Desta forma, ao substituir as variáveis da equação (6) para as variáveis deste trabalho, encontramos a regressão abaixo:

$\operatorname{Ln}\left(\mathrm{s}_{\mathrm{t}, \mathrm{t}+\mathrm{k}} / \mathrm{s}_{\mathrm{t}}\right)=\alpha+\beta\left(\left(\operatorname{Ln}\left(1+\operatorname{swap} \operatorname{DIxPRE}_{\mathrm{t}, \mathrm{t}+\mathrm{k}}\right)-\operatorname{Ln}(1+\right.\right.$ Zero Cupom Yield $\mathrm{t}, \mathrm{t}+\mathrm{k}))+\boldsymbol{\varepsilon} \mathrm{t,t+ \textrm {k }}$

em que $\operatorname{Ln}\left(\mathrm{s}_{\mathrm{t}, \mathrm{t}+\mathrm{k}} / \mathrm{S}_{\mathrm{t}}\right)$ é o logaritmo da variação cambial entre o tempo $\mathrm{t} \mathrm{e}$ $\mathrm{t}+\mathrm{k}$, Ln (1+ swap DIxPRE) o logaritmo da curva swap DIxPRE no período entre $\mathrm{t}$ e $\mathrm{t}+\mathrm{k}$ e Ln(1+Zero Cupom Yield t,t+k) o logaritimo da curva Zero Cupom Yield no período de $\mathrm{t}$ e $\mathrm{t}+\mathrm{k}$ e $\boldsymbol{\varepsilon} \mathrm{t}, \mathrm{t}+\mathrm{k} \mathrm{o}$ erro aleatório.

No entanto, primeiramente foi realizado a análise das variáveis. Uma análise preliminar de desvio padrão, correlação entre as variáveis, coeficiente de curtose, assimetria, teste Jaque-Bera destaca a relação entre as variáveis assim como características das séries temporais.

Posteriormente, foi analisado a estacionariedade das variáveis diferenças de taxa de juros (variável exógena) e variação do câmbio (variável endógena). De forma a verificar se a série é estacionária, o teste de raiz unitária foi aplicado através do teste de Dickey-Fuller.

Para os casos de séries não estacionárias, foi verificado a estacionariedade da primeira diferença de forma que o modelo de regressão apenas utilize séries estacionárias.

Após a verificação e ajustes das séries não estacionárias, o modelo de regressão foi aplicado. As principais análises do modelo envolvem o beta, alfa, teste Wald, desvio padrão de beta e do alfa.

O teste Wald, foi utilizado para testar duas hipóteses, sendo a principal delas a hipótese de "eficiência" $\left(H_{0}: \alpha=0, \beta=1\right)$ no qual é possível verificar se o modelo 
de paridade descoberta de taxa de juros é rejeitado. Desta forma, para os casos em que em que o valor $\mathrm{p}$ da estatística $\mathrm{F}$ for menor que 0,1 , o teste é rejeitado ao nível de significância a 10\%. Adicionalmente, foi testado a hipótese nula $\mathrm{H}_{\mathrm{o}}$ : $\beta=1$, no qual o alfa da regressão é isolado da análise.

Por fim, através das análises dos resultados das regressões é possível verificar se há lucratividade da operação de carry trade para os diferentes prazos analisados conforme o período entre 2005 e2016.

O resultado do carry trade pode ser analisado através da fórmula (8) que neste trabalho será apresentado por último através de uma figura de retorno ao longo do período analisado.

$$
\operatorname{Ln}\left(\mathrm{s}_{\mathrm{t}, \mathrm{t}+\mathrm{k}} / \mathrm{s}_{\mathrm{t}}\right)+((\operatorname{Ln}(1+\text { swap DIxPRE})-\operatorname{Ln}(1+\text { Zero Cupom Yield }))
$$

\subsection{Coleta de Dados}

As bases de dados para a pesquisa tiveram como origem o Banco Central do Brasil, Bolsa de Valores Brasileira B3 e o sistema Reuters. Os dados de taxa de câmbio do país têm como origem o Banco Central do Brasil. Assim como destacado em outros estudos tais como Chinn \& Menzie (2006) existe a dificuldade de obter ativos com mesma maturidade entre países. Desta forma, considerou-se neste estudo as curvas de juros para os prazos de carry trade, 1,2,3,4 e 5 anos. Importante ressaltar que taxação, controle de capitais e demais custos que possam impactar a rentabilidade da taxa de juros não foram considerados neste estudo.

A meta de taxa de juros dos Estados Unidos Fed Funds é determinada pelo FED (Federal Reserve) através do Comitê de Política Monetária (Federal Open Market Commite - FOMC) expressa em dia corridos. Esta taxa serve de balizamento para as taxas interbancárias. No entanto, este trabalho utilizou uma curva de juros zero cupom yield americana visto que a meta de taxa de juros é uma série e não projeta a taxa de juros para o futuro. A curva de juros teve como fonte a Reuters.

O Brasil tem a meta de taxa de juros estipulada internamente. A meta SELIC é divulgada pelo COPOM (Conselho de Política Monetária), órgão do BACEN, e sua divulgação reflete nas taxas interbancárias. A reunião do COPOM ocorre a cada 45 dias no qual é analisada a necessidade de alteração da taxa de juros. Este trabalho, no entanto, irá utilizar a curva de juros swap DIxPRE que projeta a curva de juros para diferentes vértices. Esta curva estima a taxa de juros para o período a 
ser analisado. O dado foi obtido pela bolsa brasileira, B3. A taxa de juros brasileira, porém, diferente de grande parte dos países, é calculada como padrão por dia útil na base 252 considerando juros composto.

As metas de taxas de juros estão expostas na figura 1, assim como a visualização da diferença de taxa de juros entre os países que constam neste trabalho, figura 2.

Figura 1 - Meta Taxa de Juros Brasil e Estados Unidos

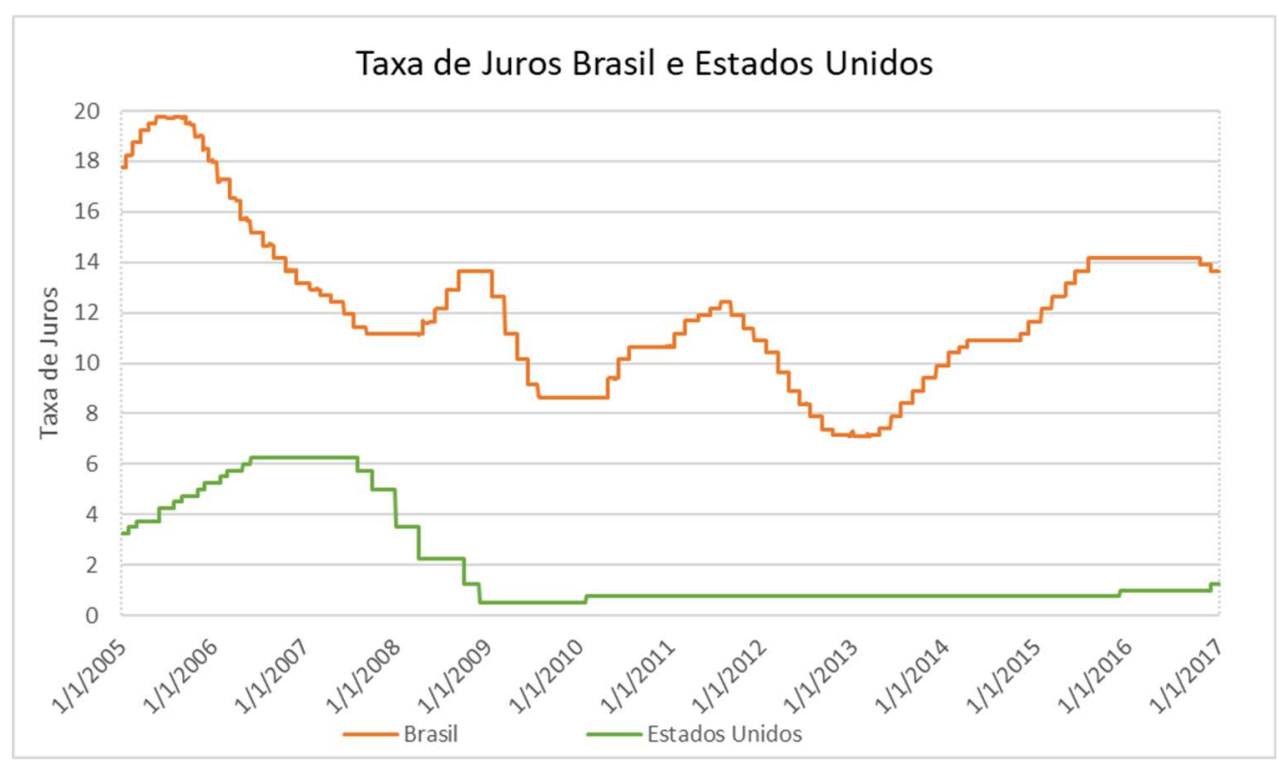

Fonte: Thomson Reuters, FRED Economic Data

Figura 2 - Diferença de Taxa de Juros Brasil x Estados Unidos

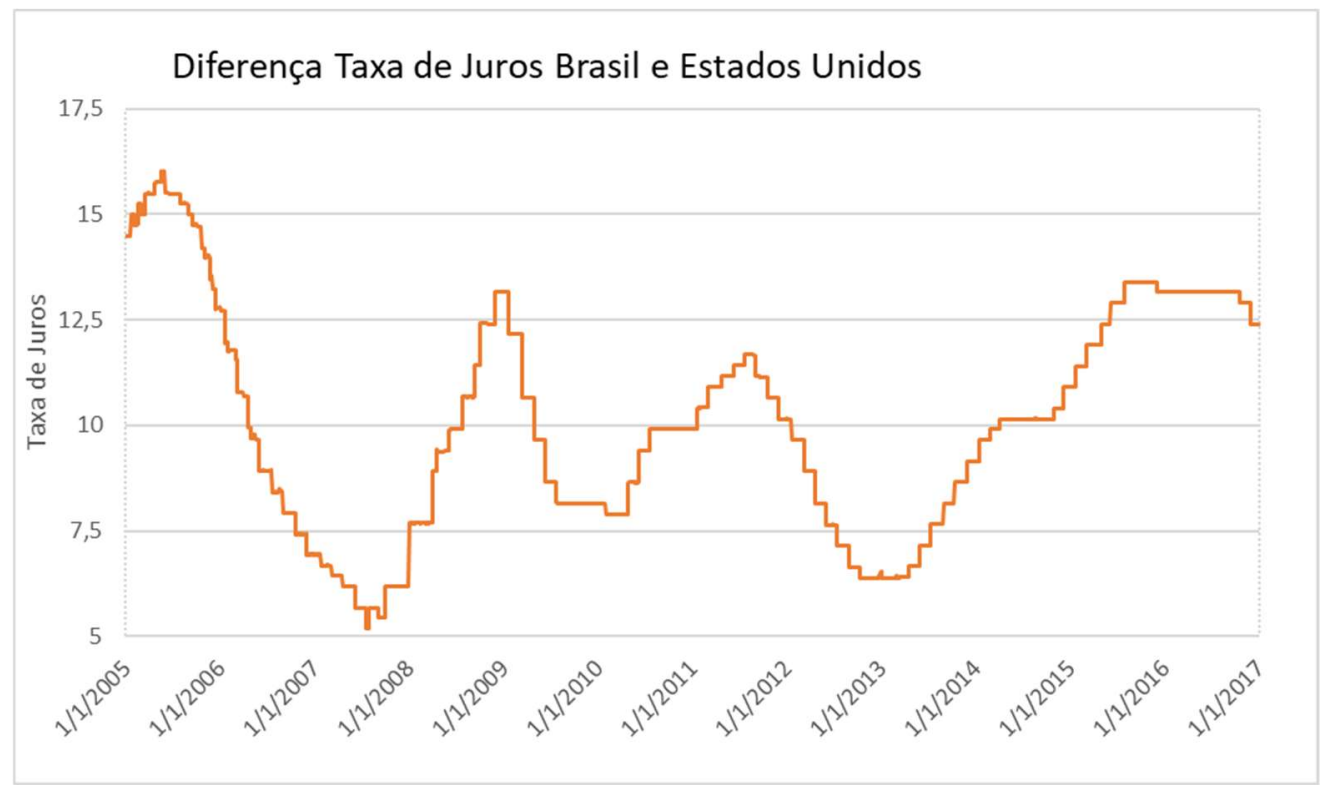

Fonte: Thomson Reuters, FRED Economic Data 


\section{Desenvolvimento}

A análise do período 2005 a 2016 foi realizada de forma a verificar o impacto na atividade de carry trade com a crise 2008. Neste período, foram analisados os períodos de longo prazo de 1,2,3,4 e 5 anos. Logo para o investidor que abrir uma operação de carry trade em 2016 com prazos de 5 anos terá a mesma encerrada apenas em 2016, motivo pelo qual as figuras 1,2,3 e 4 apresentam os dados até o ano de 2016.

Com referência ao período em destaque, 2005 a2016, é possível observar que a cotação do real frente ao dólar após a falência do banco Lehman Brothers em 2008 não seguiu um padrão constante, apesar de se verificar uma tendência à desvalorização da moeda em um primeiro momento. Porém já em 2009, o real teve uma forte valorização conforme visualizado na figura 3. Desta forma, observa-se uma forte instabilidade do câmbio no período em que constam os dados. Conforme tabela 1, o dólar apresentou um desvio padrão que oscilou entre $16,5 \%$ e 39,4\% para os prazos de 1 a 5 anos. As variações do câmbio também foram discrepantes conforme tabela 1 , com variações mínimas e máximas para os prazos de 1 a 5 anos de $-29,20 \%$ e $87,70 \%$ respectivamente.

Figura 3 - Retorno câmbio Real/Dólar (2005-2016)

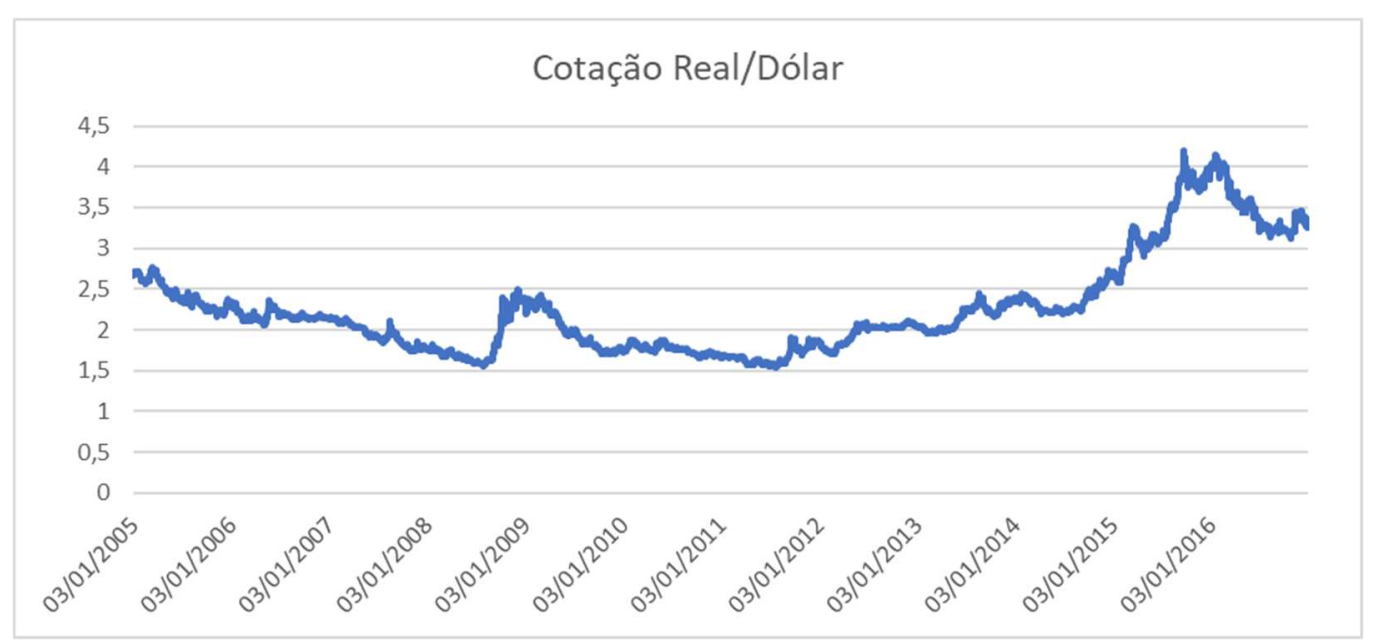

Fonte: elaboração própria com dados do Banco Central

A instabilidade do câmbio foi acompanhada da instabilidade da taxa de juros do Brasil. Após a crise 2008 observou-se momentos de alta e de baixa da taxa SELIC conforme pode ser visualizado na figura 1. 
O teste de Jaque-Bera no qual testa a normalidade das séries não seguiu uma tendência para as séries de retorno de câmbio. Considerando um nível de significância igual a 10\% observada na tabela 1 referente ao campo p valor, apenas os prazos de 2 e 3 anos do retorno do câmbio apresentaram séries normais. Por outro lado, o resultado das curvas de juros do Brasil e Estados Unidos para o teste de Jaque Bera, conforme tabela 2, foi rejeitado a 10\% de significância o que mostra a normalidade das séries de curvas de juros.

As curvas de taxas de juros brasileiras e retorno do câmbio apresentaram assimetria positiva enquanto a taxa de juros americana apresentou valores próximos de zero o que mostra uma série mais simétrica. O teste de curtose para todas as séries apresentou curtose platicúrtica, ou seja, séries menos concentradas do que a distribuição normal.

Tabela 1 - Estatísticas dos Retornos da variação cambial (R\$ / US\$) - 2005 a 2016

\begin{tabular}{|l|r|r|r|r|r|}
\hline & $\Delta \mathrm{st}, \mathrm{t}+1$ & $\Delta \mathrm{st}, \mathrm{t}+2$ & $\Delta \mathrm{st}, \mathrm{t}+3$ & $\Delta \mathrm{st}, \mathrm{t}+4$ & $\Delta \mathrm{st}, \mathrm{t}+5$ \\
\hline Mediana & $-0,025$ & $-0,027$ & $-0,002$ & 0,080 & 0,161 \\
\hline Média & $-0,062$ & 0,010 & $-0,017$ & 0,009 & 0,127 \\
\hline Máximo & 0,347 & 0,411 & 0,372 & 0,818 & 0,877 \\
\hline Minimo & $-0,302$ & $-0,356$ & $-0,436$ & $-0,292$ & $-0,421$ \\
\hline Desvio Padrão & 0,165 & 0,194 & 0,227 & 0,315 & 0,394 \\
\hline Assimetria & 0,574 & 0,022 & 0,030 & 0,804 & 0,336 \\
\hline Curtose & 2,287 & 1,961 & 2,161 & 2,546 & 1,887 \\
\hline Jarque-Bera & 6,399 & 3,782 & 2,475 & 9,781 & 5,915 \\
\hline p-valor & 0,041 & 0,151 & 0,290 & 0,008 & 0,052 \\
\hline Observações & 84 & 84 & 84 & 84 & 84 \\
\hline
\end{tabular}

Fonte: Elaboração própria com base nos resultados do Eviews

Tabela 2 - Estatísticas dos Retornos das curvas de juros do Brasil e Estados Unidos - 2005 a 2016

\begin{tabular}{|c|c|c|c|c|c|c|c|c|c|c|}
\hline & BRA & BRA & $i_{3}$ BRA & 4 BRA & $i_{5}$ BRA & $i_{1}$ EUA & $i 2^{\mathrm{EUA}}$ & $i_{3}$ EUA & $i_{4}$ EUA & 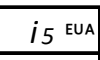 \\
\hline edi & 121 & 247 & 0,371 & 496 & 619 & 0,027 & 0,056 & 090 & 126 & \\
\hline lédi & 115 & 235 & 0,355 & 0,475 & 595 & 028 &, 058 & 98 & 36 & \\
\hline háx & 76 & 0,336 & 0,491 & 0,643 & 0,802 & 0,056 & 0,110 & 158 & 07 & \\
\hline is & & & 0 , & 39 & & & 10 & 19 & & \\
\hline esv & 024 & 0,040 & 0,053 & 0,065 & 77 & 0,020 & 335 & 46 & 054 & \\
\hline ssi & 323 & 747 & 0,709 & 0,695 & 57 & 0,110 & 0,052 & $-0,054$ &, 128 & 0,1 \\
\hline urt & 764 & 489 & 2,399 & 2,446 & 2,480 & 1,322 & 1,340 & 1,422 & 1,532 & 16 \\
\hline arqu & 9,675 & 8,726 & 8,312 & 7,832 & 6,993 & 10,022 & 9,679 & 8,759 & 7,776 & 5 \\
\hline -valor & 0,008 & 0,013 & 0,016 & 0,020 & 0,030 & 0,007 & 0,008 & 013 & 0,020 & \\
\hline bserva & & & & 84 & 84 & & & & 84 & \\
\hline
\end{tabular}

Fonte: Elaboração própria com base nos resultados do Eviews. 
As curvas de juros adicionalmente são correlatas conforme tabela 3. As correlações das curvas de juros entre o Brasil e Estados Unidos são positivas, no qual a menor correlação considerando o mesmo período é igual a 0,46 , prazo 5 anos, e a maior correlação igual a 0,519 para o prazo de 1 ano. Os retornos do câmbio, por outro lado, apresentaram uma correlação negativa para ambas as curvas, americana e brasileira. Ou seja, para um aumento de taxa de juros no Brasil e Estados Unidos é esperado uma valorização do câmbio real. No entanto, a correlação entre ao diferencial de taxa de juros com retorno do câmbio foi próximo a zero, conforme tabela 3 , sendo a maior e menor correlação de 0,26 e $-0,05$ para os prazos de 4 e 2 anos respectivamente. Logo, a análise é imprecisa do ponto de vista de correlação e torna-se necessária a análise conjunta da diferença de taxa de juros com o retorno do câmbio a ser analisada na regressão de mínimos quadrados ordinários (MQO).

Tabela 3 - Matriz de correlação Retorno Câmbio, Curva de Juros Brasil e Estados Unidos

\begin{tabular}{|c|c|c|c|c|c|c|c|c|c|c|c|c|c|c|c|}
\hline & $i_{1}{ }^{\mathrm{BRA}}$ & $i_{2}{ }^{\mathrm{BRA}}$ & $i_{3}{ }^{\text {BRA }}$ & $i_{4}{ }^{\mathrm{BRA}}$ & $i_{5}{ }^{\text {BRA }}$ & $i_{1}$ EUA & $i_{2}$ EUA & $i_{3} \mathrm{EUA}$ & $i_{4} \mathrm{EUA}$ & $i_{5}$ EUA & $\Delta s t, t+1$ & $\Delta \mathrm{st}_{\mathrm{t}, \mathrm{t}+2}$ & $\Delta \mathrm{st}_{\mathrm{t}, \mathrm{t}+3}$ & $\Delta \mathrm{st}_{\mathrm{t}, \mathrm{t}+4}$ & $\Delta s \mathrm{~s}, \mathrm{t}+5$ \\
\hline i1 ${ }^{\text {BRA }}$ & 1,000 & & & & & & & & & & & & & & \\
\hline i2 ${ }^{\text {BRA }}$ & 0,981 & 1,000 & & & & & & & & & & & & & \\
\hline i3 ${ }^{\text {BRA }}$ & 0,951 & 0,991 & 1,000 & & & & & & & & & & & & \\
\hline i4 ${ }^{\text {BRA }}$ & 0,921 & 0,974 & 0,995 & 1,000 & & & & & & & & & & & \\
\hline i5 ${ }^{\text {BRA }}$ & 0,893 & 0,955 & 0,984 & 0,997 & 1,000 & & & & & & & & & & \\
\hline i1 EUA & 0,519 & 0,461 & 0,433 & 0,407 & 0,393 & 1,000 & & & & & & & & & \\
\hline i2 EUA & 0,542 & 0,494 & 0,470 & 0,447 & 0,434 & 0,994 & 1,000 & & & & & & & & \\
\hline i3 EUA & 0,541 & 0,504 & 0,486 & 0,466 & 0,455 & 0,982 & 0,996 & 1,000 & & & & & & & \\
\hline i4 EUA & 0,532 & 0,503 & 0,488 & 0,470 & 0,461 & 0,970 & 0,988 & 0,998 & 1,000 & & & & & & \\
\hline i5 EUA & 0,522 & 0,497 & 0,485 & 0,468 & 0,460 & 0,957 & 0,979 & 0,993 & 0,998 & 1,000 & & & & & \\
\hline$\Delta s t, t+1$ & $-0,126$ & $-0,113$ & $-0,136$ & $-0,170$ & \begin{tabular}{|l|}
$-0,191$ \\
\end{tabular} & \begin{tabular}{|l|}
$-0,279$ \\
\end{tabular} & $-0,301$ & $-0,311$ & $-0,311$ & \begin{tabular}{|l|}
$-0,305$ \\
\end{tabular} & 1,000 & & & & \\
\hline$\Delta \mathrm{st}, \mathrm{t}+2$ & $-0,417$ & $-0,456$ & $-0,507$ & $-0,553$ & $-0,583$ & $-0,421$ & $-0,463$ & $-0,489$ & $-0,495$ & $-0,491$ & 0,607 & 1,000 & & & \\
\hline$\Delta \mathrm{st}, \mathrm{t}+3$ & $-0,545$ & $-0,530$ & $-0,533$ & $-0,546$ & $-0,554$ & $-0,626$ & $-0,653$ & $-0,666$ & $-0,662$ & \begin{tabular}{|l|}
$-0,651$ \\
\end{tabular} & 0,568 & 0,733 & 1,000 & & \\
\hline$\Delta s t, t+4$ & $-0,444$ & $-0,428$ & $-0,430$ & $-0,435$ & $-0,442$ & $-0,799$ & $-0,818$ & $-0,829$ & $-0,827$ & $-0,821$ & 0,610 & 0,754 & 0,840 & 1,000 & \\
\hline$\Delta s t, t+5$ & $-0,579$ & $-0,563$ & $-0,575$ & $-0,587$ & $-0,596$ & $-0,812$ & \begin{tabular}{|l|}
$-0,838$ \\
\end{tabular} & $\mid-0,844$ & \begin{tabular}{|l|}
$-0,837$ \\
\end{tabular} & $-0,823$ & 0,528 & 0,787 & 0,860 & 0,904 & 1,000 \\
\hline
\end{tabular}

Fonte: Elaboração própria com base nos resultados do Eviews 
Tabela 4 - Matriz de correlação Retorno Câmbio e Diferencial de Juros

\begin{tabular}{|c|c|c|c|c|c|c|c|c|c|c|}
\hline & $\Delta \mathrm{it}, \mathrm{t}+1$ & $\Delta \mathrm{i} t, \mathrm{t}+2$ & $\Delta \mathrm{it}, \mathrm{t}+3$ & $\Delta \mathrm{i}_{\mathrm{t}, \mathrm{t}+4}$ & $\Delta \mathrm{it}, \mathrm{t}+5$ & $\Delta \mathrm{st}, \mathrm{t}+1$ & $\Delta \mathrm{st}, \mathrm{t}+2$ & $\Delta \mathrm{st}, \mathrm{t}+3$ & $\Delta \mathrm{st}, \mathrm{t}+4$ & $\Delta s t, t+5$ \\
\hline$\Delta \mathrm{it}, \mathrm{t}+1$ & 1,00 & & & & & & & & & \\
\hline$\Delta \mathrm{it}, \mathrm{t}+2$ & 0,98 & 1,00 & & & & & & & & \\
\hline$\Delta \mathrm{it}, \mathrm{t}+3$ & 0,96 & 0,99 & 1,00 & & & & & & & \\
\hline$\Delta \mathrm{it}, \mathrm{t}+4$ & 0,94 & 0,98 & 0,99 & 1,00 & & & & & & \\
\hline$\Delta \mathrm{it}, \mathrm{t}+5$ & 0,91 & 0,95 & 0,98 & 0,99 & 1,00 & & & & & \\
\hline$\Delta \mathrm{st}, \mathrm{t}+1$ & 0,12 & 0,16 & 0,14 & 0,09 & 0,04 & 1,00 & & & & \\
\hline$\Delta \mathrm{st}, \mathrm{t}+2$ & $-0,07$ & $-0,05$ & $-0,08$ & $-0,15$ & $-0,22$ & 0,61 & 1,00 & & & \\
\hline$\Delta \mathrm{st}, \mathrm{t}+3$ & $-0,02$ & 0,05 & 0,05 & 0,00 & $-0,06$ & 0,57 & 0,73 & 1,00 & & \\
\hline$\Delta s t, t+4$ & 0,25 & 0,31 & 0,31 & 0,26 & 0,20 & 0,61 & 0,75 & 0,84 & 1,00 & \\
\hline$\Delta \mathrm{st}, \mathrm{t}+5$ & 0,11 & 0,19 & 0,17 & 0,11 & 0,04 & 0,53 & 0,79 & 0,86 & 0,90 & 1,00 \\
\hline
\end{tabular}

Fonte: Elaboração própria com base nos resultados do Eviews

Após a análise das estatísticas das variáveis a serem utilizadas na regressão é preciso verificar a estacionariedade das séries. O teste de Dickey Fuller Aumentado (ADF) foi realizado de forma a verificar a ordem de integração das variáveis do modelo. A hipótese nula é de que a série tenha de raiz unitária. Visto que é preciso utilizar séries estacionárias nas regressões, caso as séries não sejam estacionárias em nível é preciso verificá-las em primeira diferença.

Conforme tabela 5, é possível verificar que as variáveis são integradas de ordem 1 , ou seja, a hipótese de raiz unitária não pode ser rejeitada a $10 \%$ de significância, isto é, as variáveis não são estacionárias em nível (média e variância não são constante no tempo). A exceção, no entanto, ocorre com o retorno do câmbio e diferença de taxa de juros para o prazo de 1 ano no qual a hipótese de raiz unitária é rejeitada a 5\% de significância. Desta forma, na regressão do método de mínimos quadrados ordinários (MQO) serão utilizadas as variáveis em primeira ordem com exceção para o prazo de 1 ano.

A não estacionariedade em nível também é encontrada em outros estudos, tais como Karbel (2009) no qual retratou o carry trade no Brasil e os Estados Unidos no período de 2003 a 2008. 
Tabela 5 - Teste Dickey Fuller Aumentado (2005 -2016)

\begin{tabular}{|l|l|l|r|r|r|r|r|}
\hline \multicolumn{7}{|c|}{ Teste Raiz Unitária (Dickey-Fuller) } \\
\hline Variável & Prazo & Nivel & Valor Crítico 5\% & Valor $p$ & $1^{0}$ Diferença & Valor Crítico 5\% & Valor $p$ \\
\hline Diferença Taxa de Juros & 1 ano (2005-2011) & $-3,070$ & $-2,899115$ & 0,033 & $-4,408$ & $-2,897678$ & 0,001 \\
\hline Diferença Taxa de Juros & 2 anos (2005-2011) & $-1,958$ & $-2,897223$ & 0,305 & $-7,831$ & $-2,897223$ & 0,000 \\
\hline Diferença Taxa de Juros & 3 anos (2005-2011) & $-2,137$ & $-2,896779$ & 0,231 & $-8,521$ & $-2,897223$ & 0,000 \\
\hline Diferença Taxa de Juros & 4 anos (2005-2011) & $-2,348$ & $-2,896779$ & 0,160 & $-9,127$ & $-2,897223$ & 0,000 \\
\hline Diferença Taxa de Juros & 5 anos (2005-2011) & $-2,558$ & $-2,896779$ & 0,106 & $-9,575$ & $-2,897223$ & 0,000 \\
\hline Retorno Câmbio & 1 ano (2005-2011) & $-2,890$ & $-2,889768$ & 0,051 & $-5,009$ & $-2,902953$ & 0,000 \\
\hline Retorno Câmbio & 2 anos (2005-2011) & $-2,014$ & $-2,586103$ & 0,280 & $-8,140$ & $-2,897223$ & 0,000 \\
\hline Retorno Câmbio & 3 anos (2005-2011) & $-1,265$ & $-2,896779$ & 0,642 & $-6,966$ & $-2,897223$ & 0,000 \\
\hline Retorno Câmbio & 4 anos (2005-2011) & 0,603 & $-2,901217$ & 0,989 & $-3,635$ & $-2,90067$ & 0,007 \\
\hline Retorno Câmbio & 5 anos (2005-2011) & $-0,890$ & $-2,897223$ & 0,787 & $-7,766$ & $-2,897223$ & 0,000 \\
\hline
\end{tabular}

Fonte: Elaboração própria com base nos resultados do Eviews.

O teste de regressão, seguido da análise de Dickey-Fuller, apresentou um beta positivo apenas para o prazo de um ano conforme tabela 6 . No entanto, é importante verificar que o alto valor do desvio padrão resulta na não rejeição do $\beta=0$ conforme pode ser visualizado pelo $\mathrm{p}$ Valor igual a 0,282 , ou seja, o beta não é significativo a $10 \%$. O mesmo comportamento é verificado para o prazo de 2 anos, no qual o beta apesar de ser negativo não é significativo a $10 \%$. Os prazos de $3,4,5$ anos apresentaram beta negativo e significativo a $10 \%$, logo é possível rejeitar a hipótese nula do $\beta=0$.

Por outro lado, o alfa não foi significativo para nenhum prazo, com exceção do prazo de 5 anos com nível de significativo de $10 \%$, o que concluiu que a hipótese nula de $\alpha=0$ não pode ser rejeitado para os prazos de 1,2,3,4 anos. Este resultado, por conseguinte, está de acordo com o modelo de paridade descoberta de taxa de juros, no qual estipula $\alpha=0$.

Tabela 6 - Regressão MQO (2005-2016)

\begin{tabular}{|l|c|r|r|r|r|r|r|r|}
\hline Prazo & Beta & Desvio Padrão & Estatistica T & p Valor & Alfa & Desvio Padrão & Estatistica T & p Valor \\
\hline 1 ano & 0,904 & 0,836 & $-1,366$ & 0,282 & $-0,110$ & 0,081 & $-1,366$ & 0,176 \\
\hline 2 anos & $-0,539$ & 0,592 & $-0,911$ & 0,365 & 0,005 & 0,007 & 0,665 & 0,508 \\
\hline 3 anos & $-0,641$ & 0,319 & $-2,009$ & 0,048 & 0,008 & 0,006 & 1,392 & 0,168 \\
\hline 4 anos & $-0,431$ & 0,228 & $-1,887$ & 0,063 & 0,010 & 0,006 & 1,600 & 0,114 \\
\hline 5 anos & $-0,692$ & 0,179 & $-3,870$ & 0,000 & 0,011 & 0,006 & 1,903 & 0,061 \\
\hline
\end{tabular}

Fonte: Elaboração própria com base nos resultados do Eviews

No entanto, de forma a ter uma análise mais completa é preciso verificar a análise do teste Wald no qual testa a hipótese de "eficiência" $\left(H_{o}: \alpha=0, \beta=1\right)$. O resultado do teste Wald, conforme tabela 7 , testa a hipótese nula $H_{o}: \alpha=0, \beta=1$ da 
paridade descoberta de taxa de juros no qual foi rejeitada com nível de significância de $10 \%$ para todos os prazos.

Outro teste foi realizado de forma a verificar o beta da regressão isoladamente, considerando a hipótese nula igual a $H_{0}: \beta=1$. Neste caso, para todos os períodos, com exceção do prazo de 1 ano, a hipótese nula foi rejeitada a nível de significância de $10 \%$.

Tabela 7 - Teste Wald

\begin{tabular}{|l|r|r|r|r|}
\hline Hipótese Nula & \multicolumn{2}{|c|}{$\boldsymbol{H}_{\mathbf{o}}: \boldsymbol{\alpha}=\mathbf{0}, \boldsymbol{\beta}=\mathbf{1}$} & \multicolumn{2}{|c|}{$\boldsymbol{H}_{\mathbf{o}}: \boldsymbol{\beta}=\mathbf{1}$} \\
\hline Prazo & Estatistica $\mathrm{F}$ & $\mathbf{p}$ Valor & Estatistica $\mathrm{F}$ & $\mathbf{p}$ Valor \\
\hline 1 ano & 22,053 & 0,000 & 0,013 & 0,909 \\
\hline 2 anos & 3,752 & 0,028 & 6,760 & 0,011 \\
\hline 3 anos & 14,621 & 0,000 & 26,460 & 0,000 \\
\hline 4 anos & 21,446 & 0,000 & 39,301 & 0,000 \\
\hline 5 anos & 47,516 & 0,000 & 89,605 & 0,000 \\
\hline
\end{tabular}

Fonte: Elaboração própria com base nos resultados do Eviews

Portanto, observa-se uma predominância do beta negativo para os períodos analisados assim como rejeição do beta igual a 0 e igual a 1 . O resultado está de encontro com a figura 4 , no qual é possível verificar a lucratividade da atividade para os prazos de 3,4 e 5 anos entre o período analisado, 2005 a2016. O resultado de prazo de 1 ano, beta positivo e próximo de um, não teve a hipótese nula de beta igual a 1 e beta igual a 0 rejeitada, logo não é possível afirmar a lucratividade da operação de carry trade. Adicionalmente é possível observar na figura 4 que apenas para o prazo de 1 ano houve prejuízo do carry trade no ano de 2008 . O prazo de 2 anos, como também, não teve a hipótese nula de beta igual a 0 rejeitada o que impossibilita afirmar a lucratividade do carry trade. 
Figura 4 - Retorno Carry Trade (2005-2011)

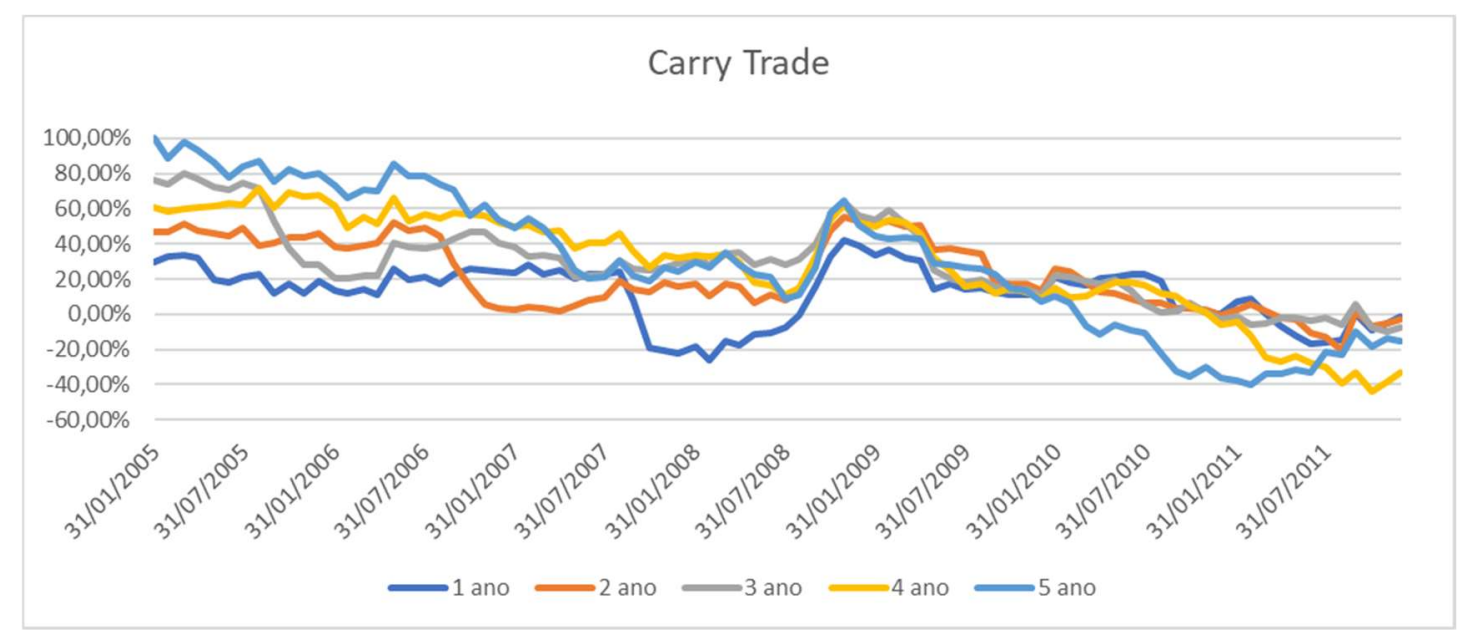

Fonte: Elaboração própria

Importante destacar que os resultados do beta para os diferentes prazos e a particularidade para o prazo de 1 ano são compreensíveis diante do período de grande oscilação do câmbio e alterações da taxa de juros. Através da figura 5 é possível verificar a dispersão da diferença de taxa de juros e depreciação do câmbio para cada prazo.

Figura 5 - Figura de dispersão de diferença de taxa de juros e depreciação da taxa de câmbio brasileira
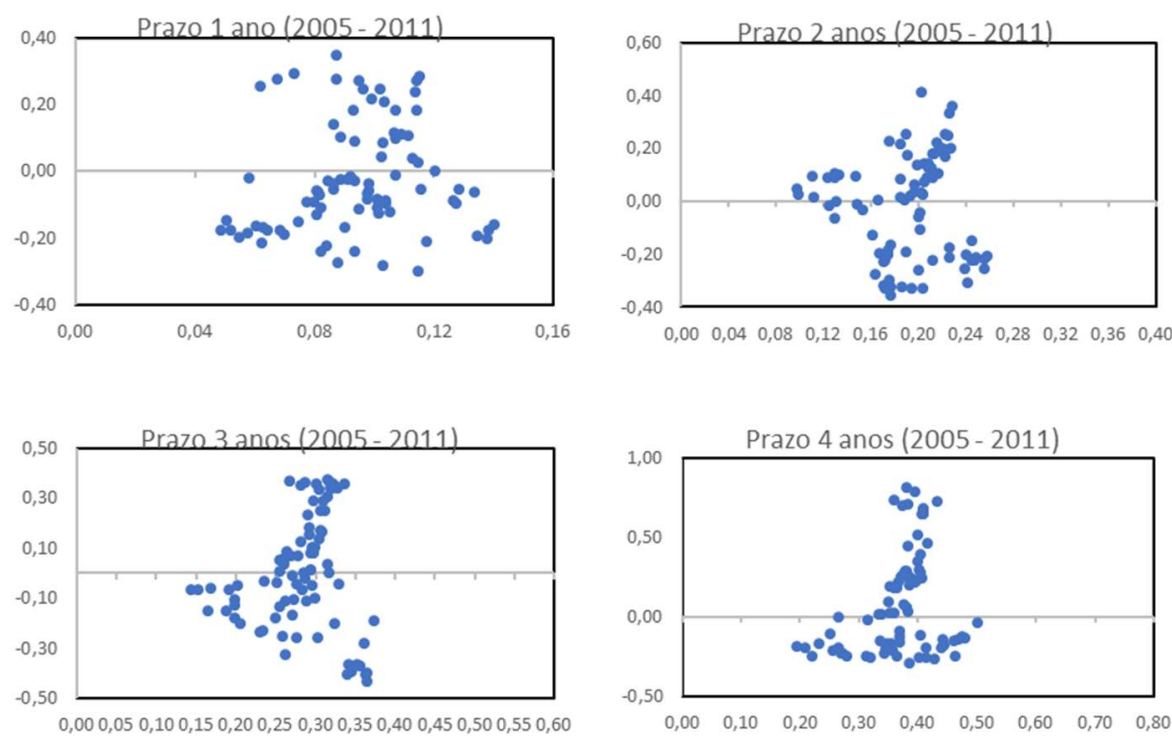


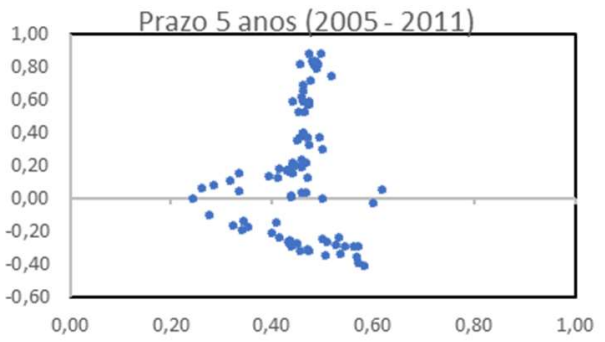

Fonte: Elaboração própria 


\section{Conclusão}

Este trabalho teve como objetivo verificar a lucratividade das operações de carry trade através do modelo de paridade descoberta de taxa de juros. A operação é lucrativa apenas para os prazos de 3,4 e 5 anos. Estes foram os prazos para os quais todas as hipóteses nulas foram rejeitadas. Para o prazo de 2 anos não foi possível rejeitar a hipótese nula de beta igual a zero e para o prazo de 1 anos não foi possível rejeitar as hipóteses nulas de beta igual a 0 e beta igual a 1 . Devido a isso, para os prazos de 1 e 2 não é possível afirmar a lucratividade da operação de carry trade para o período analisado.

Portanto, os resultados das regressões não tiveram um resultado direcionado, ou seja, houve prazos no qual foi possível afirmar a lucratividade da operação de carry trade (3,4 e 5 anos) e prazos não qual não é possível confirmar essa afirmação (1 e 2 anos). Por outro lado, através da análise da figura 4 é possível verificar os retornos descrentes da atividade ao longo dos anos e para todos os prazos. Ademais, após o ano de 2010 é visível a tendência à retornos negativos.

Os resultados das regressões também devem levar em consideração a grande oscilação da diferença de taxa de juros entre os países no qual teve variações superiores a $10 \%$. Desta forma, o período analisado apresentou grandes variações nas duas variáveis analisadas: diferença de taxa de juros e variação do câmbio.

Ademais, este trabalho teve como foco a verificação da paridade descoberta de taxa de juros para períodos de longo prazo, ou seja, prazos igual ou superiores a um ano. Grande parte da literatura, por sua vez, realiza estudos para períodos de curto prazo devido à dificuldade de obtenção de dados de longo prazo. Este estudo, de forma a contornar este ponto, utilizou curvas de juros para estimar a taxa de juros de longo prazo.

Porém, é necessário observar que a ausência de séries de taxa de juros que espelham diretamente o retorno de ativos negociados podem gerar ruídos nas séries assim como destacado por Chinn \& Menzie (2006).

Karbel (2009) em seu estudo, assim como verificado neste trabalho, também utilizou o Brasil como moeda alvo e Estados Unidos como moeda de financiamento, no entanto entre o período de 2000 a 2003 e 2003 a 2008, períodos pré-crise 2008. O resultado do seu estudo mostrou que a paridade descoberta de taxa de juros não pode ser rejeitada para o período de 2000 a 2003 e pode ser 
rejeitada para o período de 2003 a 2008 o que torna possível a lucratividade da operação de carry trade para este período.

Como sugestão para os próximos estudos, é importante a análise do carry trade em períodos antes, durante e pós-crise e impactos que geram nesta atividade para diferentes países. Neste trabalho, foi possível observar que o resultado da atividade se mostrou diferente para os prazos analisados.

Adicionalmente, uma sugestão para estudos sobre o tema é incluir análises adicionais do impacto da inflação na taxa de juros dos países assim como verificação de outras variáveis. Froot \& Thaler (1990) já destaca que uma alta expectativa de inflação reflete em uma maior incerteza no futuro da política monetária, assim como uma mudança da taxa de juros local pode produzir um aumento do prêmio de risco na operação de carry trade. 


\section{Referências bibliográficas}

ALMEIDA, Cássia. Temor do mercado de vitória de Lula nas eleições de 2002 faz dólar subir até 76\%. O Globo, Rio de Janeiro, 16 mar. 2016. Disponível em: <http://acervo.oglobo.globo.com/em-destaque/temor-domercado-de-vitoria-de-lula-nas-eleicoes-de-2002-faz-dolar-subir-ate-7618892882>. Acesso em 22 Outubro 2017.

BUI, Anh Tuan. Test of the Uncovered Interest Parity: Evidence from Australia and New Zealand. Journal of Economic Literature, jul. 2010.

BIS PAPERS. Basel: Bank for International Settlements, n. 81, abr. 2015. ISSN 1682-7651.

CARVALHO, Jaimilton; DIVINO, José Angelo. Paridade descoberta da taxa de juros em países latino-americanos. Pesquisa e Planejamento Econômico, v. 39, n. 2, 2009.

CIEPLINSKI, Andre; BRAGA, Julia; SUMMA, Ricardo. Estimação do teorema da paridade descoberta da taxa de juros para o Brasil. Working paper, mar. 2015.2 Disponível em: <http://www.ie.ufrj.br/images/pesquisa/publicacoes/discussao/2015/TD_IE _004_2015_CIEPLINSKI_BRAGA_SUMMA.pdf>. Acesso em 22 Outubro 2017.

CHINN, Menzie D. The (partial) rehabilitation of interest rate parity in the floating rate era: Longer horizons, alternative expectations, and emerging markets. Journal of International Money and Finance, 2006, p. 7-21.

CHINN, Menzie D.; MEREDITH, Guy. Testing Uncovered Interest Parity at Short and Long Horizons during the Post-Bretton Woods Era. National Bureau of Economic Research, n. 11077, jan. 2005.

. Monetary Policy and Long - Horizon Uncovered Interest Parity. IMF Staff Papers, v. 51, p. 409-30, 2004.

EDWARDS, Sebastian; KHAN, Mohsin S. Interest rate determination in developing countries: a conceptual framework. IMF Staff Papers, v. 32, p. 377-403, 1985.

FAMA, Eugene Francis. Forward and spot exchange rates. Journal of Monetary Economics, 1984.

FRANKEL, Jeffrey A. Quantifying International Capital Mobility in the 1980s. NBER Working Paper, n. 2856, jan. 1991. Disponível em: <http://www.nber.org/chapters/c5993>. Acesso em 22 Outubro 2017.

FROOT, Kenneth A.; THALER, Richard H. Foreign Exchange. Journal of Economic Perspectives, v. 4, n. 3, p. 179-92, verão 1990. 
GALATI, Gabriele; Health, Alexandra; McGuire, Patrick. Evidence od carry trade activity. BIS Quarterly Review, Basel, set. 2007, p. 27-41. Disponível em: <https://www.bis.org/publ/qtrpdf/r_qt0709.pdf>. Acesso em 22 Outubro 2017.

GALHARDO, Ricardo. Lula: crise é tsunami nos EUA e, se chegar ao Brasil, será 'marolinha'. O Globo, Rio de Janeiro, 04 out. 2008. Disponível em: $<$ https://oglobo.globo.com/economia/lula-crise-tsunami-nos-eua-sechegar-ao-brasil-sera-marolinha-3827410>. Acesso em 22 Outubro 2017.

GARCIA, Márcio; DIDIER, Tatiana. Taxa de Juros, Risco Cambial e Risco Brasil. IPEA, 2000.

GARCIA, Márcio; OLIVARES, Gino. O prêmio de risco da taxa de câmbio no Brasil durante o Plano Real. Revista Brasileira de Economia, v. 55, n. 2, p. 151-182, 2001.

GYNTELBERG, J.; REMOLONA, E. M. Risk in Carry Trades: Look at Target Currencies in Asia and the Pacific. BIS Quarterly Review, Basel, dez. 2007, p. 73-82. Disponível em: <https://www.bis.org/publ/qtrpdf/r_qt0712.pdf>. Acesso em 22 Outubro 2017.

KARBEL, Marcelo Voloch. Um teste da paridade descoberta da taxa de juros no Brasil pós real. 2009. 55f. Dissertação (mestrado profissional) Programa de Pós Graduação em Economia, CAEN, Universidade Federal do Ceará, Fortaleza-CE, 2009. Disponível em: $<$ http://www.repositorio.ufc.br/handle/riufc/5683>. Acesso em 22 Outubro 2017.

HANSEN, Lars Peter. Large Sample Properties of Generalized Method of Moments Estimators. Econometrica, Nova lorque, v. 50, n. 4, p. 10291054, jul. 1982. Disponível em: <http://www.jstor.org/stable/1912775>. Acesso em 22 Outubro 2017.

MCCALLUM, B. T. A Reconsideration of the Uncovered Interest Parity Relationship. Journal of Monetary Economics, v. 3, p. 105-32, fev. 1994.

PIRES, Selma Sousa. A crise financeira internacional de 2008 e seus desdobramentos sobre a economia brasileira. In: IV Jornada Internacional de Políticas Públicas. 2013, São Luiz. Anais... São Luís: UFMA, 2013.

SILVA, Guilherme Ricardo dos Santos Souza; CURADO, Marcelo Luiz. Comportamento da taxa de câmbio no brasil: uma análise a partir da paridade descoberta da taxa de juros. Revista Análise Econômica, Porto Alegre, v. 31, n. 59, 2013. Disponível em: $<$ http://seer.ufrgs.br/index.php/AnaliseEconomica/article/view/17145/2467 0>. Acesso em 22 Outubro 2017. 
TSE. Yiuman; ZHAO, Lin. The relationship between currency carry trade and U.S Stocks. Journal of Futures Markets, v. 32, mar. 2012.

ZHANG, Yanchun. Does the Horizon Matter? - The Uncovered Interest Parity Reconsidered". International Journal of Applied Economics, set. 2006, p. 61-79.

ZURAWSKI, Andrew; D'ARCY, Patrick. Japanese Retail Investors and the Carry Trade. Bulletin, mar. 2009. 


\section{Anexos}

Tabela 8 - Séries swap DIxPRE, Zero Cupom Yield e Retorno do Câmbio (2005-2016)

\begin{tabular}{|c|c|c|c|c|c|c|}
\hline & & Prazo 1 ano (2005-20 & 011) & & Prazo 2 ano (2005-20 & 011) \\
\hline Data & SWAP DIXPRE & Zero Cupom Yield & Retorno Câmbio & SWAP DIXPRE & Zero Cupom Yield & Retorno Câmbio \\
\hline $31 / 01 / 2005$ & 0,17 & 0,03 & $-0,16$ & 0,33 & 0,07 & $-0,21$ \\
\hline $28 / 02 / 2005$ & 0,17 & 0,04 & $-0,20$ & 0,32 & 0,08 & $-0,22$ \\
\hline $31 / 03 / 2005$ & 0,18 & 0,04 & $-0,20$ & 0,34 & 0,08 & $-0,25$ \\
\hline $29 / 04 / 2005$ & 0,18 & 0,04 & $-0,18$ & 0,33 & 0,08 & $-0,22$ \\
\hline $31 / 05 / 2005$ & 0,17 & 0,04 & $-0,07$ & 0,32 & 0,08 & $-0,21$ \\
\hline $30 / 06 / 2005$ & 0,17 & 0,04 & $-0,05$ & 0,32 & 0,08 & $-0,20$ \\
\hline $29 / 07 / 2005$ & 0,17 & 0,04 & $-0,09$ & 0,32 & 0,08 & $-0,25$ \\
\hline $31 / 08 / 2005$ & 0,17 & 0,04 & $-0,10$ & 0,33 & 0,08 & $-0,15$ \\
\hline $30 / 09 / 2005$ & 0,16 & 0,04 & 0,00 & 0,31 & 0,09 & $-0,18$ \\
\hline $31 / 10 / 2005$ & 0,16 & 0,05 & $-0,05$ & 0,32 & 0,09 & $-0,21$ \\
\hline $30 / 11 / 2005$ & 0,15 & 0,05 & $-0,01$ & 0,30 & 0,09 & $-0,22$ \\
\hline 29/12/2005 & 0,15 & 0,05 & $-0,09$ & 0,29 & 0,09 & $-0,26$ \\
\hline $31 / 01 / 2006$ & 0,15 & 0,05 & $-0,04$ & 0,28 & 0,09 & $-0,19$ \\
\hline $24 / 02 / 2006$ & 0,14 & 0,05 & $-0,03$ & 0,27 & 0,10 & $-0,20$ \\
\hline $31 / 03 / 2006$ & 0,14 & 0,05 & $-0,05$ & 0,27 & 0,10 & $-0,22$ \\
\hline $28 / 04 / 2006$ & 0,14 & 0,05 & $-0,03$ & 0,27 & 0,10 & $-0,23$ \\
\hline $31 / 05 / 2006$ & 0,14 & 0,05 & $-0,17$ & 0,30 & 0,10 & $-0,33$ \\
\hline $30 / 06 / 2006$ & 0,14 & 0,06 & $-0,11$ & 0,28 & 0,11 & $-0,30$ \\
\hline $31 / 07 / 2006$ & 0,14 & 0,05 & $-0,13$ & 0,27 & 0,10 & $-0,32$ \\
\hline $31 / 08 / 2006$ & 0,13 & 0,05 & $-0,09$ & 0,26 & 0,10 & $-0,28$ \\
\hline $29 / 09 / 2006$ & 0,13 & 0,05 & $-0,15$ & 0,26 & 0,10 & $-0,13$ \\
\hline $31 / 10 / 2006$ & 0,12 & 0,05 & $-0,19$ & 0,25 & 0,10 & $-0,01$ \\
\hline $30 / 11 / 2006$ & 0,12 & 0,05 & $-0,18$ & 0,24 & 0,10 & 0,09 \\
\hline $28 / 12 / 2006$ & 0,12 & 0,05 & $-0,18$ & 0,23 & 0,10 & 0,10 \\
\hline $31 / 01 / 2007$ & 0,12 & 0,05 & $-0,17$ & 0,23 & 0,10 & 0,10 \\
\hline $28 / 02 / 2007$ & 0,11 & 0,05 & $-0,22$ & 0,23 & 0,10 & 0,09 \\
\hline $30 / 03 / 2007$ & 0,11 & 0,05 & $-0,16$ & 0,22 & 0,10 & 0,09 \\
\hline $30 / 04 / 2007$ & 0,11 & 0,05 & $-0,20$ & 0,21 & 0,10 & 0,09 \\
\hline $31 / 05 / 2007$ & 0,10 & 0,05 & $-0,15$ & 0,20 & 0,10 & 0,05 \\
\hline $29 / 06 / 2007$ & 0,10 & 0,05 & $-0,18$ & 0,20 & 0,10 & 0,02 \\
\hline $31 / 07 / 2007$ & 0,10 & 0,05 & $-0,18$ & 0,21 & 0,10 & 0,02 \\
\hline $31 / 08 / 2007$ & 0,11 & 0,05 & $-0,19$ & 0,22 & 0,09 & $-0,06$ \\
\hline $28 / 09 / 2007$ & 0,11 & 0,05 & $-0,02$ & 0,21 & 0,09 & $-0,02$ \\
\hline $31 / 10 / 2007$ & 0,11 & 0,05 & 0,26 & 0,22 & 0,09 & 0,00 \\
\hline $30 / 11 / 2007$ & 0,11 & 0,04 & 0,28 & 0,23 & 0,08 & $-0,03$ \\
\hline $28 / 12 / 2007$ & 0,11 & 0,04 & 0,29 & 0,24 & 0,08 & 0,01 \\
\hline
\end{tabular}




\begin{tabular}{|c|c|c|c|c|c|c|}
\hline & & $005-20$ & & & $005-20$ & \\
\hline $31 / 01 / 2008$ & 0,11 & 0,03 & 0,27 & 0,24 & 0,06 & 0,01 \\
\hline $29 / 02 / 2008$ & 0,11 & 0,03 & 0,35 & 0,24 & 0,05 & 0,08 \\
\hline $31 / 03 / 2008$ & 0,12 & 0,02 & 0,25 & 0,25 & 0,05 & 0,03 \\
\hline $30 / 04 / 2008$ & 0,12 & 0,03 & 0,27 & 0,26 & 0,06 & 0,04 \\
\hline $30 / 05 / 2008$ & 0,13 & 0,03 & 0,22 & 0,27 & 0,07 & 0,14 \\
\hline $30 / 06 / 2008$ & 0,13 & 0,03 & 0,21 & 0,29 & 0,07 & 0,10 \\
\hline $31 / 07 / 2008$ & 0,14 & 0,03 & 0,18 & 0,27 & 0,07 & 0,13 \\
\hline $29 / 08 / 2008$ & 0,14 & 0,03 & 0,12 & 0,27 & 0,06 & 0,07 \\
\hline $30 / 09 / 2008$ & 0,13 & 0,04 & $-0,06$ & 0,27 & 0,07 & $-0,11$ \\
\hline $31 / 10 / 2008$ & 0,14 & 0,03 & $-0,21$ & 0,30 & 0,05 & $-0,22$ \\
\hline $28 / 11 / 2008$ & 0,13 & 0,02 & $-0,30$ & 0,28 & 0,04 & $-0,31$ \\
\hline $26 / 12 / 2008$ & 0,12 & 0,01 & $-0,28$ & 0,23 & 0,03 & $-0,33$ \\
\hline $30 / 01 / 2009$ & 0,11 & 0,01 & $-0,24$ & 0,22 & 0,03 & $-0,33$ \\
\hline $27 / 02 / 2009$ & 0,10 & 0,01 & $-0,28$ & 0,21 & 0,03 & $-0,36$ \\
\hline $31 / 03 / 2009$ & 0,09 & 0,01 & $-0,24$ & 0,20 & 0,03 & $-0,33$ \\
\hline $30 / 04 / 2009$ & 0,09 & 0,01 & $-0,22$ & 0,20 & 0,03 & $-0,33$ \\
\hline $29 / 05 / 2009$ & 0,09 & 0,01 & $-0,06$ & 0,19 & 0,03 & $-0,20$ \\
\hline $30 / 06 / 2009$ & 0,09 & 0,01 & $-0,09$ & 0,20 & 0,03 & $-0,20$ \\
\hline $31 / 07 / 2009$ & 0,09 & 0,01 & $-0,06$ & 0,20 & 0,03 & $-0,18$ \\
\hline $31 / 08 / 2009$ & 0,09 & 0,01 & $-0,07$ & 0,20 & 0,03 & $-0,16$ \\
\hline $30 / 09 / 2009$ & 0,09 & 0,01 & $-0,04$ & 0,21 & 0,03 & 0,00 \\
\hline $30 / 10 / 2009$ & 0,09 & 0,01 & $-0,02$ & 0,22 & 0,02 & 0,02 \\
\hline $30 / 11 / 2009$ & 0,10 & 0,00 & $-0,02$ & 0,22 & 0,02 & 0,03 \\
\hline $30 / 12 / 2009$ & 0,10 & 0,01 & $-0,03$ & 0,22 & 0,03 & 0,06 \\
\hline $29 / 01 / 2010$ & 0,10 & 0,00 & $-0,11$ & 0,22 & 0,02 & $-0,06$ \\
\hline $26 / 02 / 2010$ & 0,10 & 0,00 & $-0,08$ & 0,22 & 0,02 & $-0,04$ \\
\hline $31 / 03 / 2010$ & 0,10 & 0,01 & $-0,07$ & 0,22 & 0,02 & 0,03 \\
\hline $30 / 04 / 2010$ & 0,11 & 0,01 & $-0,10$ & 0,23 & 0,02 & 0,09 \\
\hline $28 / 05 / 2010$ & 0,11 & 0,01 & $-0,11$ & 0,23 & 0,02 & 0,09 \\
\hline $30 / 06 / 2010$ & 0,11 & 0,01 & $-0,12$ & 0,23 & 0,02 & 0,13 \\
\hline $30 / 07 / 2010$ & 0,11 & 0,00 & $-0,13$ & 0,22 & 0,01 & 0,14 \\
\hline $31 / 08 / 2010$ & 0,11 & 0,00 & $-0,09$ & 0,22 & 0,01 & 0,14 \\
\hline $30 / 09 / 2010$ & 0,11 & 0,00 & 0,09 & 0,22 & 0,01 & 0,18 \\
\hline $29 / 10 / 2010$ & 0,11 & 0,00 & 0,04 & 0,22 & 0,01 & 0,18 \\
\hline $30 / 11 / 2010$ & 0,11 & 0,01 & 0,10 & 0,23 & 0,02 & 0,19 \\
\hline $30 / 12 / 2010$ & 0,11 & 0,00 & 0,11 & 0,23 & 0,02 & 0,22 \\
\hline $31 / 01 / 2011$ & 0,12 & 0,00 & 0,04 & 0,24 & 0,02 & 0,20 \\
\hline $28 / 02 / 2011$ & 0,12 & 0,00 & 0,03 & 0,24 & 0,02 & 0,17 \\
\hline $31 / 03 / 2011$ & 0,12 & 0,00 & 0,11 & 0,24 & 0,02 & 0,20 \\
\hline $29 / 04 / 2011$ & 0,12 & 0,00 & 0,18 & 0,24 & 0,02 & 0,25 \\
\hline $31 / 05 / 2011$ & 0,12 & 0,00 & 0,24 & 0,24 & 0,01 & 0,25 \\
\hline $30 / 06 / 2011$ & 0,12 & 0,00 & 0,28 & 0,24 & 0,01 & 0,33 \\
\hline 29/07/2011 & 0,12 & 0,00 & 0,27 & 0,24 & 0,01 & 0,36 \\
\hline $31 / 08 / 2011$ & 0,11 & 0,00 & 0,25 & 0,21 & 0,01 & 0,41 \\
\hline $30 / 09 / 2011$ & 0,10 & 0,01 & 0,09 & 0,20 & 0,01 & 0,17 \\
\hline $31 / 10 / 2011$ & 0,10 & 0,01 & 0,18 & 0,20 & 0,01 & 0,25 \\
\hline $30 / 11 / 2011$ & 0,09 & 0,01 & 0,14 & 0,19 & 0,01 & 0,22 \\
\hline $29 / 12 / 2011$ & 0,10 & 0,01 & 0,10 & 0,20 & 0,02 & 0,22 \\
\hline
\end{tabular}




\begin{tabular}{|c|c|c|c|c|c|c|}
\hline & \multicolumn{3}{|c|}{ Prazo 3 ano (2005-2011) } & \multicolumn{3}{|c|}{ Prazo 4 ano (2005-2011) } \\
\hline Data & SWAP DIXPRE & Zero Cupom Yield & Retorno Câmbio & SWAP DIXPRE & Zero Cupom Yield & Retorno Câmbio \\
\hline $31 / 01 / 2005$ & 0,47 & 0,11 & $-0,40$ & 0,62 & 0,15 & $-0,13$ \\
\hline $28 / 02 / 2005$ & 0,46 & 0,12 & $-0,40$ & 0,60 & 0,16 & $-0,15$ \\
\hline $31 / 03 / 2005$ & 0,49 & 0,13 & $-0,44$ & 0,64 & 0,17 & $-0,13$ \\
\hline 29/04/2005 & 0,48 & 0,12 & $-0,41$ & 0,63 & 0,16 & $-0,14$ \\
\hline $31 / 05 / 2005$ & 0,47 & 0,12 & $-0,37$ & 0,61 & 0,15 & $-0,16$ \\
\hline $30 / 06 / 2005$ & 0,46 & 0,12 & $-0,37$ & 0,60 & 0,15 & $-0,19$ \\
\hline $29 / 07 / 2005$ & 0,47 & 0,13 & $-0,41$ & 0,61 & 0,17 & $-0,18$ \\
\hline $31 / 08 / 2005$ & 0,47 & 0,12 & $-0,37$ & 0,62 & 0,16 & $-0,25$ \\
\hline $30 / 09 / 2005$ & 0,45 & 0,13 & $-0,20$ & 0,59 & 0,17 & $-0,20$ \\
\hline $31 / 10 / 2005$ & 0,47 & 0,14 & $-0,05$ & 0,61 & 0,18 & $-0,26$ \\
\hline $30 / 11 / 2005$ & 0,45 & 0,14 & 0,03 & 0,59 & 0,18 & $-0,26$ \\
\hline $29 / 12 / 2005$ & 0,43 & 0,14 & 0,01 & 0,56 & 0,18 & $-0,29$ \\
\hline $31 / 01 / 2006$ & 0,42 & 0,14 & 0,07 & 0,55 & 0,18 & $-0,25$ \\
\hline $24 / 02 / 2006$ & 0,40 & 0,14 & 0,05 & 0,52 & 0,19 & $-0,15$ \\
\hline $31 / 03 / 2006$ & 0,41 & 0,15 & 0,04 & 0,54 & 0,19 & $-0,20$ \\
\hline $28 / 04 / 2006$ & 0,41 & 0,15 & 0,04 & 0,55 & 0,20 & $-0,17$ \\
\hline $31 / 05 / 2006$ & 0,45 & 0,15 & $-0,10$ & 0,60 & 0,20 & $-0,25$ \\
\hline $30 / 06 / 2006$ & 0,43 & 0,16 & $-0,11$ & 0,58 & 0,21 & $-0,16$ \\
\hline $31 / 07 / 2006$ & 0,41 & 0,15 & $-0,11$ & 0,56 & 0,20 & $-0,21$ \\
\hline $31 / 08 / 2006$ & 0,40 & 0,15 & $-0,14$ & 0,53 & 0,19 & $-0,20$ \\
\hline $29 / 09 / 2006$ & 0,39 & 0,14 & $-0,18$ & 0,53 & 0,19 & $-0,23$ \\
\hline $31 / 10 / 2006$ & 0,38 & 0,14 & $-0,23$ & 0,51 & 0,19 & $-0,25$ \\
\hline $30 / 11 / 2006$ & 0,37 & 0,14 & $-0,24$ & 0,49 & 0,18 & $-0,24$ \\
\hline $28 / 12 / 2006$ & 0,35 & 0,14 & $-0,20$ & 0,47 & 0,19 & $-0,24$ \\
\hline $31 / 01 / 2007$ & 0,35 & 0,15 & $-0,18$ & 0,46 & 0,19 & $-0,23$ \\
\hline $28 / 02 / 2007$ & 0,34 & 0,14 & $-0,13$ & 0,45 & 0,18 & $-0,23$ \\
\hline $30 / 03 / 2007$ & 0,33 & 0,14 & $-0,15$ & 0,44 & 0,18 & $-0,21$ \\
\hline $30 / 04 / 2007$ & 0,30 & 0,14 & $-0,15$ & 0,40 & 0,18 & $-0,25$ \\
\hline $31 / 05 / 2007$ & 0,29 & 0,15 & $-0,07$ & 0,39 & 0,20 & $-0,18$ \\
\hline $29 / 06 / 2007$ & 0,30 & 0,15 & $-0,07$ & 0,41 & 0,20 & $-0,20$ \\
\hline $31 / 07 / 2007$ & 0,31 & 0,15 & $-0,06$ & 0,42 & 0,19 & $-0,17$ \\
\hline $31 / 08 / 2007$ & 0,34 & 0,14 & $-0,11$ & 0,45 & 0,18 & $-0,19$ \\
\hline $28 / 09 / 2007$ & 0,32 & 0,13 & $-0,07$ & 0,43 & 0,18 & $-0,10$ \\
\hline $31 / 10 / 2007$ & 0,33 & 0,13 & $-0,05$ & 0,44 & 0,18 & 0,00 \\
\hline $30 / 11 / 2007$ & 0,35 & 0,11 & $-0,03$ & 0,47 & 0,15 & $-0,02$ \\
\hline $28 / 12 / 2007$ & 0,37 & 0,11 & $-0,04$ & 0,49 & 0,15 & 0,02 \\
\hline
\end{tabular}




\begin{tabular}{|c|c|c|c|c|c|c|}
\hline & \multicolumn{3}{|c|}{ Prazo 3 ano (2005-2011) } & \multicolumn{3}{|c|}{ Prazo 4 ano (2005-2011) } \\
\hline $31 / 01 / 2008$ & 0,36 & 0,09 & $-0,05$ & 0,48 & 0,12 & 0,02 \\
\hline $29 / 02 / 2008$ & 0,35 & 0,08 & $-0,01$ & 0,47 & 0,12 & 0,02 \\
\hline $31 / 03 / 2008$ & 0,38 & 0,08 & $-0,05$ & 0,50 & 0,12 & 0,04 \\
\hline $30 / 04 / 2008$ & 0,38 & 0,10 & $-0,07$ & 0,51 & 0,14 & 0,08 \\
\hline $30 / 05 / 2008$ & 0,39 & 0,11 & 0,00 & 0,52 & 0,15 & 0,18 \\
\hline $30 / 06 / 2008$ & 0,43 & 0,11 & 0,00 & 0,56 & 0,15 & 0,25 \\
\hline $31 / 07 / 2008$ & 0,40 & 0,11 & 0,01 & 0,53 & 0,15 & 0,26 \\
\hline $29 / 08 / 2008$ & 0,39 & 0,11 & $-0,02$ & 0,51 & 0,15 & 0,22 \\
\hline $30 / 09 / 2008$ & 0,40 & 0,11 & $-0,11$ & 0,53 & 0,15 & 0,06 \\
\hline $31 / 10 / 2008$ & 0,47 & 0,09 & $-0,19$ & 0,64 & 0,14 & $-0,04$ \\
\hline $28 / 11 / 2008$ & 0,43 & 0,07 & $-0,28$ & 0,58 & 0,10 & $-0,14$ \\
\hline $26 / 12 / 2008$ & 0,36 & 0,05 & $-0,26$ & 0,48 & 0,08 & $-0,12$ \\
\hline $30 / 01 / 2009$ & 0,33 & 0,06 & $-0,26$ & 0,46 & 0,09 & $-0,13$ \\
\hline $27 / 02 / 2009$ & 0,32 & 0,06 & $-0,33$ & 0,44 & 0,09 & $-0,18$ \\
\hline $31 / 03 / 2009$ & 0,31 & 0,05 & $-0,25$ & 0,43 & 0,08 & $-0,17$ \\
\hline $30 / 04 / 2009$ & 0,33 & 0,06 & $-0,17$ & 0,46 & 0,09 & $-0,09$ \\
\hline $29 / 05 / 2009$ & 0,31 & 0,06 & 0,01 & 0,43 & 0,09 & 0,02 \\
\hline $30 / 06 / 2009$ & 0,32 & 0,06 & 0,06 & 0,45 & 0,10 & 0,10 \\
\hline $31 / 07 / 2009$ & 0,33 & 0,06 & 0,08 & 0,45 & 0,10 & 0,19 \\
\hline $31 / 08 / 2009$ & 0,33 & 0,06 & 0,07 & 0,45 & 0,10 & 0,19 \\
\hline $30 / 09 / 2009$ & 0,34 & 0,06 & 0,12 & 0,46 & 0,09 & 0,25 \\
\hline $30 / 10 / 2009$ & 0,35 & 0,05 & 0,16 & 0,48 & 0,09 & 0,23 \\
\hline $30 / 11 / 2009$ & 0,35 & 0,05 & 0,16 & 0,48 & 0,08 & 0,28 \\
\hline $30 / 12 / 2009$ & 0,35 & 0,06 & 0,18 & 0,48 & 0,10 & 0,29 \\
\hline $29 / 01 / 2010$ & 0,35 & 0,05 & 0,08 & 0,47 & 0,09 & 0,24 \\
\hline $26 / 02 / 2010$ & 0,34 & 0,05 & 0,08 & 0,47 & 0,09 & 0,29 \\
\hline $31 / 03 / 2010$ & 0,34 & 0,05 & 0,10 & 0,46 & 0,08 & 0,27 \\
\hline $30 / 04 / 2010$ & 0,36 & 0,05 & 0,13 & 0,47 & 0,09 & 0,25 \\
\hline $28 / 05 / 2010$ & 0,35 & 0,05 & 0,10 & 0,46 & 0,08 & 0,20 \\
\hline $30 / 06 / 2010$ & 0,35 & 0,04 & 0,17 & 0,46 & 0,07 & 0,22 \\
\hline $30 / 07 / 2010$ & 0,34 & 0,03 & 0,25 & 0,45 & 0,06 & 0,23 \\
\hline $31 / 08 / 2010$ & 0,33 & 0,03 & 0,29 & 0,43 & 0,05 & 0,26 \\
\hline $30 / 09 / 2010$ & 0,34 & 0,03 & 0,29 & 0,45 & 0,05 & 0,30 \\
\hline $29 / 10 / 2010$ & 0,33 & 0,02 & 0,25 & 0,44 & 0,04 & 0,35 \\
\hline $30 / 11 / 2010$ & 0,35 & 0,03 & 0,31 & 0,46 & 0,05 & 0,39 \\
\hline $30 / 12 / 2010$ & 0,34 & 0,04 & 0,33 & 0,45 & 0,07 & 0,45 \\
\hline $31 / 01 / 2011$ & 0,36 & 0,04 & 0,34 & 0,48 & 0,07 & 0,46 \\
\hline $28 / 02 / 2011$ & 0,36 & 0,04 & 0,37 & 0,47 & 0,08 & 0,52 \\
\hline $31 / 03 / 2011$ & 0,36 & 0,05 & 0,37 & 0,49 & 0,08 & 0,65 \\
\hline $29 / 04 / 2011$ & 0,36 & 0,04 & 0,34 & 0,48 & 0,07 & 0,67 \\
\hline $31 / 05 / 2011$ & 0,35 & 0,03 & 0,34 & 0,47 & 0,06 & 0,65 \\
\hline $30 / 06 / 2011$ & 0,36 & 0,03 & 0,36 & 0,47 & 0,06 & 0,69 \\
\hline $29 / 07 / 2011$ & 0,36 & 0,03 & 0,35 & 0,48 & 0,05 & 0,73 \\
\hline $31 / 08 / 2011$ & 0,32 & 0,02 & 0,36 & 0,43 & 0,04 & 0,79 \\
\hline $30 / 09 / 2011$ & 0,31 & 0,02 & 0,23 & 0,42 & 0,04 & 0,71 \\
\hline $31 / 10 / 2011$ & 0,31 & 0,02 & 0,36 & 0,42 & 0,04 & 0,82 \\
\hline $30 / 11 / 2011$ & 0,29 & 0,02 & 0,37 & 0,40 & 0,04 & 0,74 \\
\hline $29 / 12 / 2011$ & 0,31 & 0,03 & 0,35 & 0,41 & 0,04 & 0,70 \\
\hline
\end{tabular}




\begin{tabular}{|c|c|c|c|}
\hline \multirow[b]{2}{*}{ Data } & \multicolumn{3}{|c|}{ Prazo 5 ano (2005-2011) } \\
\hline & SWAP DIXPRE & Zero Cupom Yield & Retorno Câmbio \\
\hline $31 / 01 / 2005$ & 0,77 & 0,19 & $-0,42$ \\
\hline $28 / 02 / 2005$ & 0,74 & 0,20 & $-0,35$ \\
\hline $31 / 03 / 2005$ & 0,78 & 0,21 & $-0,40$ \\
\hline $29 / 04 / 2005$ & 0,77 & 0,20 & $-0,37$ \\
\hline $31 / 05 / 2005$ & 0,75 & 0,19 & $-0,30$ \\
\hline $30 / 06 / 2005$ & 0,73 & 0,19 & $-0,24$ \\
\hline $29 / 07 / 2005$ & 0,75 & 0,21 & $-0,30$ \\
\hline $31 / 08 / 2005$ & 0,77 & 0,20 & $-0,30$ \\
\hline $30 / 09 / 2005$ & 0,71 & 0,21 & $-0,25$ \\
\hline $31 / 10 / 2005$ & 0,75 & 0,22 & $-0,29$ \\
\hline $30 / 11 / 2005$ & 0,73 & 0,22 & $-0,27$ \\
\hline $29 / 12 / 2005$ & 0,70 & 0,22 & $-0,32$ \\
\hline $31 / 01 / 2006$ & 0,67 & 0,22 & $-0,28$ \\
\hline $24 / 02 / 2006$ & 0,65 & 0,23 & $-0,24$ \\
\hline $31 / 03 / 2006$ & 0,68 & 0,24 & $-0,27$ \\
\hline $28 / 04 / 2006$ & 0,68 & 0,24 & $-0,26$ \\
\hline $31 / 05 / 2006$ & 0,75 & 0,25 & $-0,35$ \\
\hline $30 / 06 / 2006$ & 0,72 & 0,25 & $-0,31$ \\
\hline $31 / 07 / 2006$ & 0,70 & 0,24 & $-0,33$ \\
\hline $31 / 08 / 2006$ & 0,67 & 0,23 & $-0,30$ \\
\hline $29 / 09 / 2006$ & 0,66 & 0,23 & $-0,27$ \\
\hline $31 / 10 / 2006$ & 0,64 & 0,23 & $-0,15$ \\
\hline $30 / 11 / 2006$ & 0,62 & 0,22 & $-0,22$ \\
\hline $28 / 12 / 2006$ & 0,58 & 0,23 & $-0,18$ \\
\hline $31 / 01 / 2007$ & 0,58 & 0,24 & $-0,15$ \\
\hline $28 / 02 / 2007$ & 0,57 & 0,23 & $-0,20$ \\
\hline $30 / 03 / 2007$ & 0,55 & 0,23 & $-0,17$ \\
\hline $30 / 04 / 2007$ & 0,50 & 0,23 & $-0,11$ \\
\hline $31 / 05 / 2007$ & 0,48 & 0,24 & 0,00 \\
\hline $29 / 06 / 2007$ & 0,51 & 0,25 & 0,06 \\
\hline $31 / 07 / 2007$ & 0,53 & 0,24 & 0,07 \\
\hline $31 / 08 / 2007$ & 0,56 & 0,22 & 0,03 \\
\hline $28 / 09 / 2007$ & 0,54 & 0,22 & 0,10 \\
\hline $31 / 10 / 2007$ & 0,55 & 0,22 & 0,15 \\
\hline $30 / 11 / 2007$ & 0,59 & 0,19 & 0,13 \\
\hline $28 / 12 / 2007$ & 0,61 & 0,19 & 0,18 \\
\hline
\end{tabular}




\begin{tabular}{|c|c|c|c|}
\hline & \multicolumn{3}{|c|}{ Prazo 5 ano (2005-2011) } \\
\hline $31 / 01 / 2008$ & 0,61 & 0,16 & 0,15 \\
\hline $29 / 02 / 2008$ & 0,59 & 0,16 & 0,17 \\
\hline $31 / 03 / 2008$ & 0,63 & 0,16 & 0,12 \\
\hline $30 / 04 / 2008$ & 0,64 & 0,18 & 0,18 \\
\hline $30 / 05 / 2008$ & 0,64 & 0,19 & 0,21 \\
\hline $30 / 06 / 2008$ & 0,70 & 0,20 & 0,29 \\
\hline $31 / 07 / 2008$ & 0,65 & 0,19 & 0,37 \\
\hline $29 / 08 / 2008$ & 0,64 & 0,19 & 0,34 \\
\hline $30 / 09 / 2008$ & 0,66 & 0,19 & 0,21 \\
\hline $31 / 10 / 2008$ & 0,80 & 0,18 & 0,04 \\
\hline $28 / 11 / 2008$ & 0,73 & 0,13 & $-0,04$ \\
\hline $26 / 12 / 2008$ & 0,60 & 0,10 & $-0,01$ \\
\hline $30 / 01 / 2009$ & 0,58 & 0,12 & 0,03 \\
\hline $27 / 02 / 2009$ & 0,57 & 0,13 & 0,01 \\
\hline $31 / 03 / 2009$ & 0,55 & 0,11 & 0,00 \\
\hline $30 / 04 / 2009$ & 0,58 & 0,12 & 0,03 \\
\hline $29 / 05 / 2009$ & 0,55 & 0,14 & 0,12 \\
\hline $30 / 06 / 2009$ & 0,58 & 0,14 & 0,16 \\
\hline $31 / 07 / 2009$ & 0,57 & 0,14 & 0,17 \\
\hline $31 / 08 / 2009$ & 0,58 & 0,13 & 0,19 \\
\hline $30 / 09 / 2009$ & 0,58 & 0,13 & 0,23 \\
\hline $30 / 10 / 2009$ & 0,60 & 0,13 & 0,32 \\
\hline $30 / 11 / 2009$ & 0,61 & 0,11 & 0,36 \\
\hline $30 / 12 / 2009$ & 0,60 & 0,14 & 0,39 \\
\hline $29 / 01 / 2010$ & 0,60 & 0,13 & 0,37 \\
\hline $26 / 02 / 2010$ & 0,59 & 0,12 & 0,40 \\
\hline $31 / 03 / 2010$ & 0,58 & 0,12 & 0,52 \\
\hline $30 / 04 / 2010$ & 0,59 & 0,13 & 0,58 \\
\hline $28 / 05 / 2010$ & 0,58 & 0,12 & 0,52 \\
\hline $30 / 06 / 2010$ & 0,57 & 0,10 & 0,56 \\
\hline $30 / 07 / 2010$ & 0,56 & 0,09 & 0,58 \\
\hline $31 / 08 / 2010$ & 0,54 & 0,08 & 0,69 \\
\hline $30 / 09 / 2010$ & 0,56 & 0,07 & 0,81 \\
\hline $29 / 10 / 2010$ & 0,55 & 0,07 & 0,83 \\
\hline $30 / 11 / 2010$ & 0,57 & 0,09 & 0,79 \\
\hline $30 / 12 / 2010$ & 0,56 & 0,11 & 0,81 \\
\hline $31 / 01 / 2011$ & 0,60 & 0,11 & 0,87 \\
\hline $28 / 02 / 2011$ & 0,59 & 0,11 & 0,88 \\
\hline $31 / 03 / 2011$ & 0,61 & 0,12 & 0,83 \\
\hline $29 / 04 / 2011$ & 0,59 & 0,10 & 0,82 \\
\hline $31 / 05 / 2011$ & 0,58 & 0,09 & 0,81 \\
\hline $30 / 06 / 2011$ & 0,59 & 0,10 & 0,82 \\
\hline $29 / 07 / 2011$ & 0,60 & 0,08 & 0,74 \\
\hline $31 / 08 / 2011$ & 0,54 & 0,06 & 0,71 \\
\hline $30 / 09 / 2011$ & 0,53 & 0,06 & 0,57 \\
\hline $31 / 10 / 2011$ & 0,53 & 0,06 & 0,65 \\
\hline $30 / 11 / 2011$ & 0,51 & 0,06 & 0,58 \\
\hline $29 / 12 / 2011$ & 0,52 & 0,06 & 0,61 \\
\hline
\end{tabular}

